Conference Proceedings for

\title{
Workshop on Radiological Surveys in Support of the Edgemont Clean-up Action Program
}

Held at Denver, Colorado January 21-22, 1981

Prepared by R. W. Perkins, Workshop Chairman, J. A. Young,

P. O. Jackson, V. W. Thomas, L. C. Schwendiman

Sponsored by

Office of Nuclear Material Safety and Safeguards

U.S. Nuclear Regulatory Commission

Proceedings prepared by

Pacific Northwest Laboratory

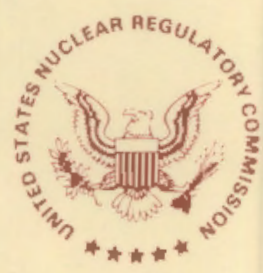




\section{Workshop on Radiological Surveys in Support of the Edgemont Clean-up Action Program}

Held at Denver, Colorado January 21-22, 1981

Manuscript Completed: April 1981

Date Published: October 1981

Prepared by

R. W. Perkins, Workshop Chairman, J. A. Young,

P. O. Jacksan, V. W. Thomas, L. C. Schwendiman

Sponsored by Office of Nuclear Material Safety and Safeguards U.S. Nuclear Regulatory Commission

Washington, D.C. 20555

Proceedings prepared by Pacific Northwest Laboratory Richland, WA 99352 


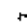




\section{PREFACE}

The Nuclear Reguiatory Commission, Office of Nuclear Material Safety and Safeguards, has given Pacific Northwest Laboratory (PNL) the responsibility for the development of procedures for the identification of offsite structures and properties in the vicinity of Edgemont, South Dakota, that require remedial action because of elevated radiation levels caused by residual radioactivity as defined in the Uranium Mill Tailings Radiation Control Act of 1978. In order to acquaint interested investigators with the procedures PNL has developed and the measurements that have been performed at Edgemont using these procedures, and also to obtain suggestions for the improvement of these procedures, PNL organized a "Workshop on Radiological Surveys in Support of the Edgemont Clean-up Action Program" on behalf of the Nuclear Regulatory Commission. This workshop was held in Denver on January 21 and 22,1981 . On the first day of the workshop an in-depth discussion of the procedures employed in the entire radiological survey program at Edgemont was held. It included a description of the equipment, techniques and procedures employed in radon daughter measurements with in structures, indoor and outdoor gamma radiation surveys, and ${ }^{226} \mathrm{Ra}$ measurements in surface and sub-surface soil samples. On the second day, the results of the measurements that have been conducted at Edgemont were presented. During the afternoon an open discussion of the radiological survey procedures used at Edgemont was held for the purpose of obtaining suggestions for the possible improvement of these procedures. Many useful suggestions were made and a few modifications in the survey procedures at Edgemont have been made in response to these suggestions. 
The comments and discussions reported in the proceedings of the workshop have been derived from notes taken by L. C. Schwendiman (PNL). Therefore, they consist of paraphrases of the actual corments by the participants, and may contain inaccuracies. They have been included because they provide valuable insights into the concerns the participants had about the radiological survey procedures, and therefore represent an important portion of the workshop. 
AGENDA FOR WORKSHOP ON RADIOLOGICAL SURVEYS IN SUPPORT

OF THE EDGEMONT CLEAN-UP ACTION PROGRAM

JANUARY 21-22, 1981

Denver Airport Hilton

Denver, Colorado

JANUARY 21, 1981

1:00 P.M. Introductory Remarks

Ross Scarano

1:15 P.M. Background information on the

Greg Eadie Edgemont site

1:30 P.M. Battelle's responsibility in the Pete Jackson/ Edgemont radiological survey or Richard Perkins

PROTOCOLS FOR RADIOLOGICAL SURVEYS

1:45 P.M. Indoor radon daughter measurements Pete Jackson

2:30 P.M. Break

2:45 P.M. Indoor gamma exposure rate Bill Thomas mea surements

3:15 P.M. Outdoor gamula exposure rate Jim Young measuremients

3:45 P.M. Radium measurements in soils Pete Jackson

4:15 P.M. Discussion of protocols 
JANUARY 22, 1981

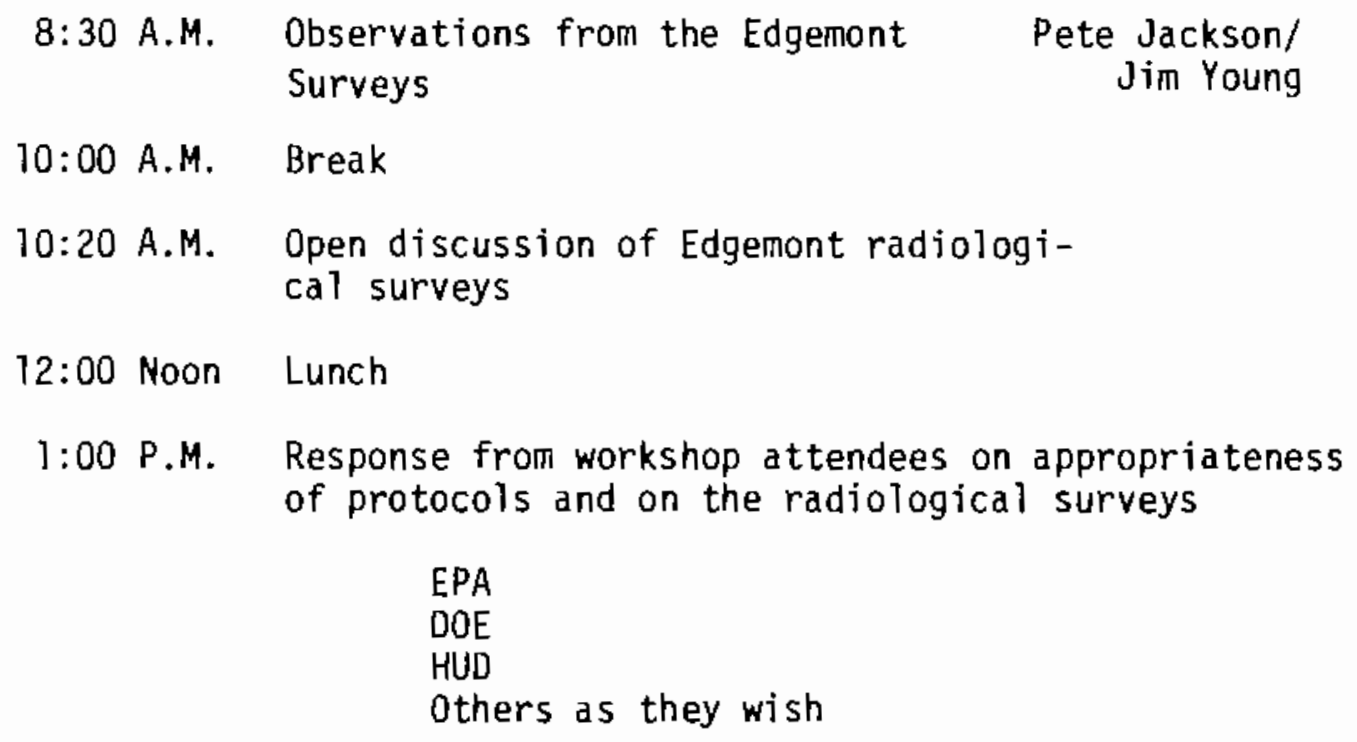




\section{TABLE OF CONTENTS}

I. INTRODUCTORY REMARKS . . . . . . . . . . . . . . . . . 1

II. PROCEDURES FOR THE DETERMINATION OF PROPERTY

REQUIRING REMEDIAL ACTION. . . . . . . . . . . . . . 2

1. Introduction................... 2

2. Mechanism for the Initiation of Radiological

Surveys. . . . . . . . . . . . . . . . . 5

a) Notification............... . 5

b) Requests for Surveys . . . . . . . . . . . . 5

c) Scheduling of Surveys............... 6

3. Five Minute Working Level Measurements in Homes. . . . . . 7

a) Introduction . . . . . . . . . . . . . . 7

b) Protocols..................... 8

c) Turnover Time of Radon Daughters in a Structure. . . 10

d) Decision Levels.................. . . 15

4. Long-Term Radon Daughter Measurements. . . . . . . . . 17

a) Introduction .................. 17

b) Protocols.................. 18

c) Discussion of Radon Daughter Measurements. . . . . . 20

5. Indoor Garmona Surveys. . . . . . . . . . . . . . . 25

a) Introduction ................. 25

b) Protocols...................... 25

6. Gamma Surveys in Garages and Nonhabitable Basements. . . 28

a) Protocols.................. . 28

b) Discussion of Indoor Gamma Surveys . . . . . . . . 29

7. Outdoor Gamma Surveys of Land with Structures. . . . . . . 29

a) Introduction ................. 29 


\section{TABLE OF CONTENTS (continued)}

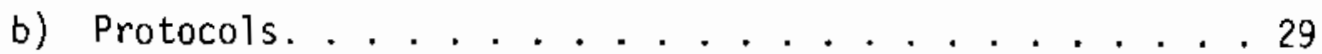

8. Gamma Surveys of Open Land . . . . . . . . . . . . 32

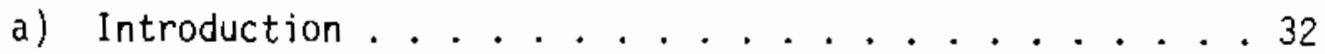

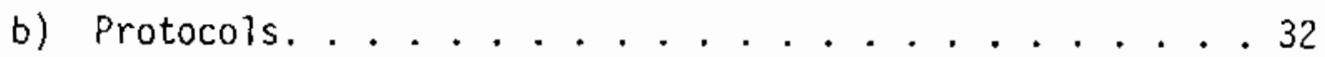

c) Discussion of Outdoor Gamma Surveys. . . . . . . . 35

9. Soit Sampling Procedures .............. 36

a) Surface Sampies. . . . . . . . . . . . . 36

b) Core Samples.................. . . 36

c) Procedure for the Anatysis of Soil for $226 \mathrm{Ra} \ldots \ldots . .37$

d) Discussion of Soil Sampling. . . . . . . . . . . 40

III. RESULTS OF RADIATION SURVEYS AT EDGEMONT . . . . . . . . . . . . 44

1. Statistical sumary. ............... 44

2. Indoor Radon Progeny Working Levels. . . . . . . . . 47

3. Indoor Gamma Surveys . . . . . . . . . . . . 57

4. Outdoor Gamma Surveys. . . . . . . . . . . . . . 57

5. ${ }^{226}$ Ra Concentrations in Soil.............. . 61

6. ${ }^{238}$ U Progeny Concentrations in Soit...........61

7. Total Number of Properties Requiring Engineering

Assessment . . . . . . . . . . . . . . 64

8. Outdoor Radon Concentrations ............. . 64

9. Open Discussion of Edgemont Protocols and Radiological Surveys. . . . . . . . . . . . . . 75

IV. CONCLUSIONS FROM WORKSHOP. . . . . . . . . . . 80

V. CHANGES IN EDGEMONT PROTOCOLS MADE AS A RESULT OF DISCUSSIONS AT THE WORKSHDP. ................. 82

VI. LIST OF ATTENDEES. . . . . . . . . . . . . . . . . . 84 


\section{INDEX OF TABLES}

Table

Page

1 Statistical Summary of Residence Units in

2 Statistical Summary of Vacant Land and Mobile

46

3 Comparison of EPA and PNL Measurements of Indoor

54 Radon Progeny Concentrations

4

Concentrations of Long- 1 ived ${ }^{238} \mathrm{U}$ Progeny in Reference Soil Samples

63

5 Disequitibrium of Long-lived $238 \mathrm{U}$ Progeny in

65 Reference Soil Samples

6

Concentration of ${ }^{238} \mathrm{U}$ Progeny in Soils Collected at Garma Anomaly Locations

66

7 Disequilibrium of ${ }^{238} \mathrm{U}$ Progeny in Soils

67

8 Measurements Requiring Engineering Assessment

68 and Total Properties Affected 

Properties Requiring Remedial Action

Frequency Distribution of Radon Progeny Turnover Times in Residences in Edgemont, S.D. Based on the Ratio: $214 \mathrm{pb} / 214 \mathrm{Bi}$

illustration of an Outdoor Gamma Survey

Gamma Survey Grid for Lots Without Structures

Frequency Distribution of all Original 5-Minute Radon Progeny Measurements

Frequency Distribution of all Original 5-Minute

Measurements of Radon Progeny in Residences

Frequency Distribution of Original 5-Minute Radon Progeny Measurements in Residences when Wind Speeds were Below $8 \mathrm{mph}$ and "Turnover Times" were Greater than 32 Minutes trations in Residences when Wind Velocities were Greater than $8 \mathrm{mph}$

10 Comparison of First and Second Radon Progeny Measurements in Structures

11 Comparison of EPA RPISU Working Level Measurements and PNL 5-Minute Measurements

14 Frequency Distribution of Maximum Gamma Exposure Rates at Outdoor "Background" Sites

15 Comparison of Outdoor Gamma Exposure Rates and 226Ra 


\section{INDEX OF FIGURES (continued)}

Figure

$\underline{\text { Page }}$

17 Average Diurnal Radon Variations at the PNL

71

Office in Edgemiont in December of 1980

18 Radon and Radon Progeny Concentrations Measured

72

in the Morning Outside the PNL Dffice

19 Radon Progeny Concentrations as Functions of Wind

74

Speed and Direction at the PNL Office in Edgemont 


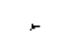




\section{INTRODUCTORY REMARKS}

Ross Scarano, Chief of Uranium Recovery Licensing Branch, Nuclear Regulatory Commission, described NRC's interest and lead role in the evaluation and clean-up, if necessary, of the property in Edgemont. TVA acquired the title to the old inactive mill site and intended to upgrade and operate the mill. Because of the impending reactivation, the mill was excluded from the Uranium Mill Tailings Remedial Action Program (UMTRAP). Initial radiological surveys were conducted by the EPA/Las Vegas using their gamma survey truck in 1972 and 1978 and by Ford, Bacon and Davis Utah Inc.

Events and reconsideration by TVA resulted in a decision not to reactivate the mill. A decision was made to have TVA decommission the mill and move the tailings to a new disposal site about two miles away. TVA was not responsible to address the question of tailings which had been moved from the tailings pile in prior years. Through the Congressional Appropriation Committee, the NRC was given the job of coordinating any clean-up needed away from the mill site (e.g., homes or vacant lots).

Mr. Scarano noted the purpose of the workshop was to review PNL's approach to monitoring radiation levels in the town itself and draw on the community of expertise assembled. He described the Edgemiont study as a one-shot, short-term effort.

Greg Eadie, NRC project manager, described the site and encouraged those attending to comment freely on the protocol. He noted that 40 CFR 192, U.S. Environmental Protection Agency's "Proposed Cleanup Standards for Inactive Uranium Processing Sites," will be used as the criteria for any remedial action. 
Richard Perkins, Associate Manager of PNL Physical Sciences Department, gave an overview of what the PNL work was to accomplish. The principal objectives were to determine which properties currently meet the 40 CFR 192 gujdelines for remedial action through field screening surveys, to identify any property which requires additional engineering assessment, to make this assessment and to participate in clean-up and post cleanup surveys. The ultimate objective being that of cleaning up all property in Edgemont according to the EPA criteria. The purpose of the workshop was to define a defensible protocol for the Edgemont radiological surveys that had the concurrence of the participants.

\section{PROCEDURES FOR THE DETERMINATION OF PROPERTY REQUIRING REMEDIAL ACTION}

\section{Introduction}

The identification of offsite structures and properties that require remedial action because of elevated radiation levels caused by residual activity is being based upon three standards proposed by the U. S. Environmental Protection Agency in 4D CFR 192, (1) "Proposed Cleanup Standards for Inactive Uranium Processing Sites". This proposed standard states that remedial action shall be required if residual radioactivity causes (1) average annual indoor radon daughter concentrations (including background) $>0.015$ working levels (WL), (2) (2) indoor gamma radiation levels $>20$ microroentgens per hour above background, or (3) average ${ }^{226}$ Ra concentrations

1 Federal Register, Vol. 45, No. 79, April 22, 1980, and Vol. 46, No. 6, January 9, 1981.

2 One working level (WL) is defined as any combination of short-lived radon decay products in 1 liter of air that will result in the ultimate emission of alpha particles with a total energy of 130 billion electron volts. 
in soil or other materials $>5 \mathrm{pCi} / \mathrm{g}$ in any $5 \mathrm{~cm}$ thickness within 1 foot of the surface, or any $15 \mathrm{~cm}$ thickness below 1 foot. If a property fails any one of these criteria because of residual radioactivity, then remedial action is required. The measurement procedures are also designed to identify properties that are not eligible for federally guaranteed financing administered by the Department of Housing and Urban Development (HUD) because of (1) indoor radon daughter weighted working levels greater than $0.02 \mathrm{WWL},(3)$ (2) average gamma exposure rates on open land greater than $14.5 \mu \mathrm{R} / \mathrm{hr}$.

The major goal of the initial radiological measurements is to locate all sources of elevated radioactivity, so that structures and properties requiring remedial action may be identified. However, the measurement procedures must, of necessity, represent a compromise between the need for accurate, representative measurements of radiological parameters, and the requirement that decisions concerning remedial action be made as quickly as possible. Any delays in carrying out remedial action caused by a too exhaustive measurement program could easily result in a greater total population dose than minor errors in deciding where remedial action is required. Therefore, some of the measurements have to be made with less than the maximum possible detail and accuracy in order to expedite the implementation of remedial action.

In the following sections, the procedures that at the present time are considered by Pacific Northwest Laboratory to represent the best compromise between expediency and accuracy are outlined. The flow diagram shown in Figure 1 outlines the measurement and decision making process. These procedures have evolved with time as experience has been gained in working level measured in a closed up structure. 
FIGURE 1: FLOW DIAGRAM OF PROCEDURES FOR DETERMINATION OF PROPERTIES REQUIRING REMEDIAL ACTION
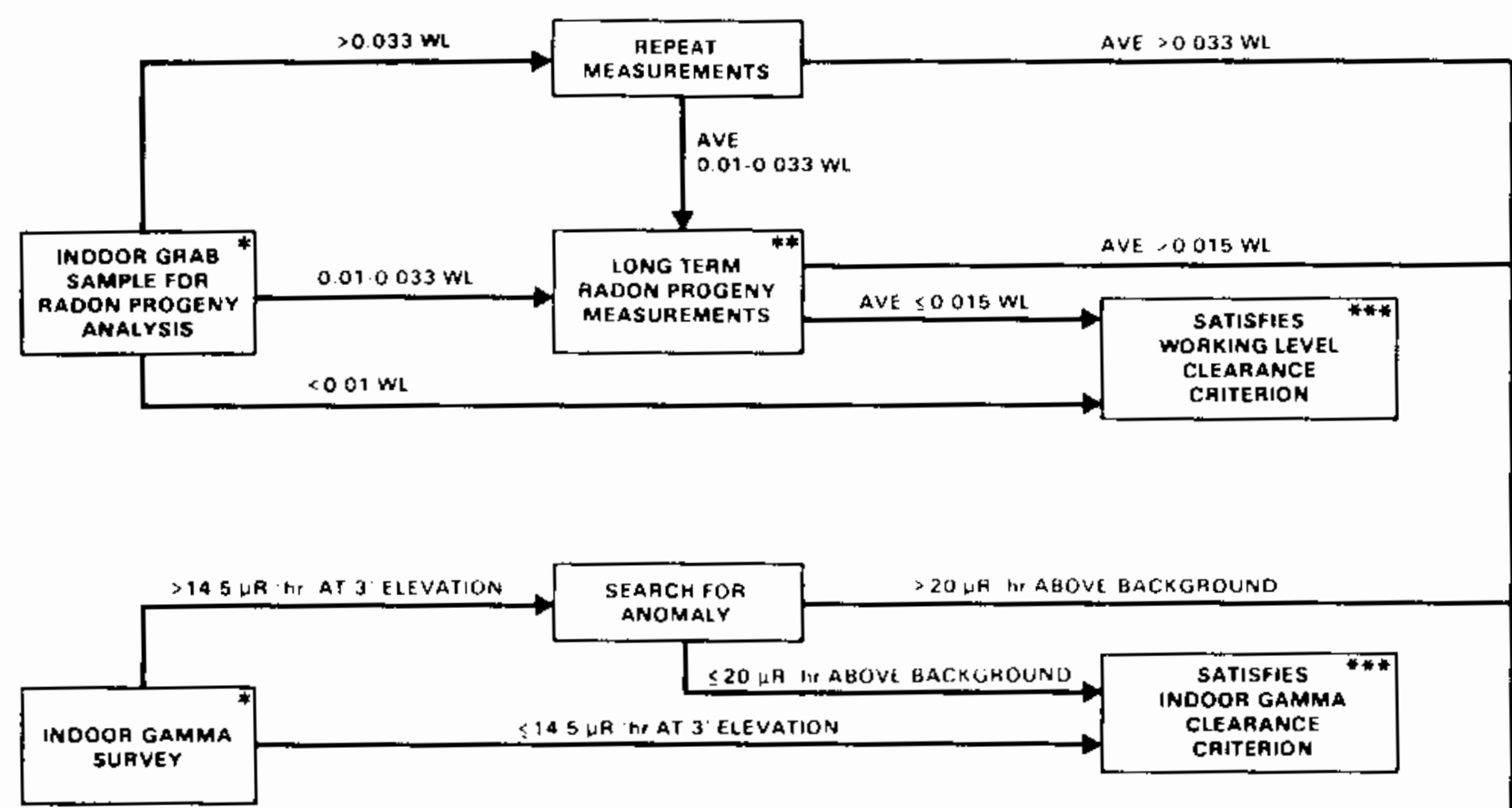

ENGINEEAING

ASSESSMENT

- gamma

SURVEY

- SOIL CORE

ANALYSIS

- bohe hole

LOGGING

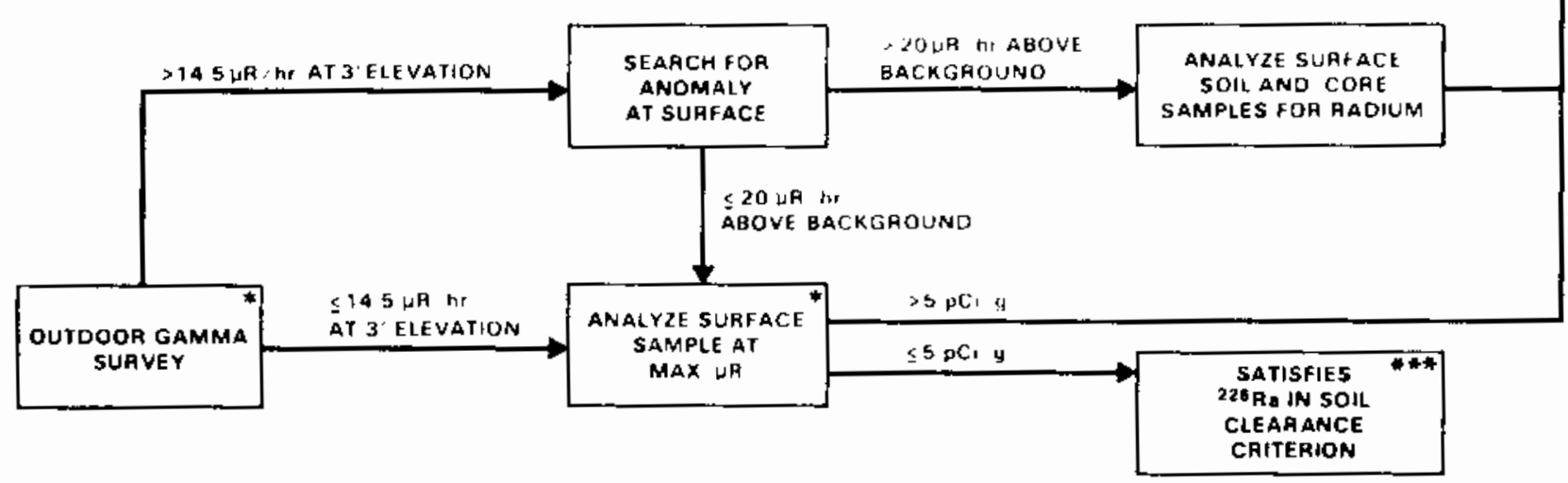

1.1 PERFORMED AT EACH PROPEATY SURVEYED

(*) NOT PERFORMEO UNLESS ALL OTHER CLEARANCES CAITERIA ARE SATISFIED

(***) ENGINEERING AS5ESSMENT IS PEAFORMEO UNLESS ALL THREE CLEARANCE CAITERIA ARE SATISFIEO 
the field, new ideas have been obtained from current literature, and discussions have been held with investigators experienced in the field. Some of the early measurements that were made using the original procedures are being repeated using current procedures. If serious discrepancies between the original and the re-measurements are observed, these re-measurements will be continued. However, if serious discrepancies are not observed, the re-measurements will be discontinued because of the time and expense involved.

2. Mechanism for the Initiation of Radiological Surveys

a) Notification

The first step in the initiation of radiological surveys at Edgemont was to inform the local residents as to the nature and purpose of the surveys. Therefore, a public meeting (with press coverage) was held at which the surveys were described.

The sign

\section{EDGEMONT CLEANUP ACTION PROGRAM}

- BATtElLE PACIFIC NORTHWEST LABORATORY

- U.S. NUCLEAR REGULATORY COMMISSION

- STATE OF SOUTH DAKOTA

was also written in bold letters on both sides of the PNL mobile laboratory to advertise our presence.

b) Requests for Surveys

Since the Edgemont program is voluntary, a property owner must first request a survey before it can be performed. Initially, the property owners either phoned or went in person to the Edgemont City Hall where the city hall staff filled out a "Radiation Hazard Evaluation, Request for Test" form. These forms were then given to PNL for the scheduling of surveys. 
Later, as the number of requests for tests had begun to lag, a paid advertisement was placed in the local newspaper. The State of South Dakota also sent a letter to each property owner who had not requested a survey, advising them that it was in their own best interest to have the survey performed. A "Radiation Hazard Evaluation Test Request" form was sent with each letter. These letters were effective in eliciting additional requests for surveys. A final letter was then sent by the City of Edgemont to those remaining property owners who did not respond to the State's letter.

c) Scheduling of Surveys

Originally, the PNL staff delivered "Consent Release and Indemnity" forms to the owner(s) of the property and any resident other than the owner when the property was to be scheduled for survey. These forms gave PNL legal permission to enter the property and perform the tests. A questionnaire describing the property was filled out by the PNL staff member using information supplied by the occupant. Later, these forms were mailed to the owners of property that had not yet been surveyed. These forms were also enclosed in the letter sent by the State of South Dakota suggesting participation in the program. No property was surveyed until the "Consent Release and Indemnity" form had been signed.

The City Planning Office at the Edgemont City Hall notified PNL which properties were to be given priority because the owner needed clearance for HUD federally guaranteed financing. These properties were surveyed as soon as possible. An attempt is made to schedule residences in clusters of up to four, because radon progeny concentrations can be measured simultaneously in 
up to four buildings at once with the PNL mobile laboratory if the four buildings are close to each other. The day before a structure is to be surveyed, the owners and/or occupants are telephoned to request permission to survey the following day. No building is surveyed unless specific pernission is obtained from both the owner and the occupants to survey on that particular day. If permission to survey is obtained, the occupant is instructed as to when and how to close up the building for the purpose of the radon progeny measurements.

3. Five-Minute Working Level Measurements in Homes

\section{a) Introduction}

The proposed clean-up standard (40 CFR 192) states that remedial action shall be required if average annual indoor radon daughter concentrations (including background) exceed $0.015 \mathrm{WL}$. However, the determination of average annual working levels requires extensive measurements over the course of a year and is therefore costly and time consuming. Therefore, to reduce the number of structures that require long-term measurements, and thereby to expedite the remedial action, five-minute radon daughter measurements under standardized conditions (windows and doors closed, air fans off) are being carried out to screen out those structures where the radon daughter concentrations are either (1) so high $(>0.033 \mathrm{WL})$ that an engineering assessment to determine the need for remedial action is clearly required, or (2) so low $(<0.010 \mathrm{WL})$ that if the proposed indoor gamma radiation exposure and average ${ }^{226} \mathrm{Ra}$ in soil standards are also satisfied, remedial action is not required. It is recognized that working levels vary considerably throughout the year, so that a single five-minute measurement cannot be used to estimate the annual average very accurately. Therefore, structures in which the radon daughter concentrations measured in five- 
minute samples are between $0.01 \mathrm{WL}$ and $0.033 \mathrm{WL}$ are being scheduled for long-term measurements using Radon Progeny Integrating Sampling Units (RPISU) to determine average working levels more accurately. Studies are aiso being initiated to determine the adequacy of Track Etch (4) devices for determining annual average working levels.

b) Protocols During the initial survey of structures at Edgemont, air filter samples are being coliected over five minute intervals for radon progeny working level measurement using $47 \mathrm{~mm}$ diameter Mi11ipore type AA filters with a pore size of 0.8 microns. Air is drawn through the filters at flow rates of about 40 liters per minute using Gast rotary vane pumps. One filter is collected in the main living area on the ground floor of each structure and one in any habitable basement. The home oners are asked to keep windows, doors and outside vents closed, and to turn off air fans, but not heating systems, for eight hours (three hours minimum) prior to making the grab working level measurements to minimize the dilution of the indoor radon progeny concentrations by outside air. Prior to measurement, the homes are checked for open doors, windows or vents, and for operating fans. If any are noticed, radon daughters are not measured in that home that day.

Commencing less than seven minutes after the beginning of radon daughter sampling, the filters are counted for three minutes using a $Z$ nS scintillator covering the entire face of a $12 \mathrm{~cm}$ diameter photomultiplier tube to determine the surn of the 
alpha emission rates of the radon progeny ${ }^{218} \rho_{0}$ and ${ }^{214} \mathrm{Po}_{0}$. Two 10-minute counts are then taken commencing $8-1 / 2$ to 12 minutes and 19 to 30 minutes after the beginning of sampling to deternine the change in the emission rate with time. The counts are stored in electronic scalers. These measurements are used to calculate the concentrations of the radon daughters ${ }^{218} \mathrm{Po},{ }^{214} \mathrm{~Pb}, 214 \mathrm{Bi}$, and ${ }^{214}$ Po and the working level by the general form of the method of Thomas, (5)

An air filter is collected each morning outside of the Battelle office at 107 N. 6th Avenue, because natural outdoor radon daughter concentrations in excess of $0.015 \mathrm{WL}$ could cause indoor concentrations to increase to the point where structures would fail the working level criterion for clearance from remedial action. However, it has been observed that outdoor radon concentrations vary with time and location at Edgemont. Therefore, beginning in February of 1981, radon daughters will be measured outside of each structure before or during the indoor radon daughter measurement. If the outdoor radon daughter concentration exceeds $0.015 \mathrm{WL}$, indoor concentrations will not be measured until the outdoor concentration falls below $0.015 \mathrm{WL}$. If it is found that the outdoor radon daughter concentration in any part of town is significantly below $0.010 \mathrm{WL}$ on a given day, no more outdoor radon daughter concentrations will be measured for the rest of that day. As soon as the necessary equipment is obtained, grab radon measurements will also be made outside and inside of the structures at the same time as the working level measurements are being made to provide information on the degree of equilibrium between radon and its daughters. 
c) Turnover Iime of Radon Daughters in a Structure

Radon daughter working levels in a structure depend not only upon the rate at which radon diffuses into the structure, but also upon both the rate of exchange of air inside the structure with outside air, and the rate of plate-out of radon daughters on the surfaces of the structure. It is possible for unusually rapid plate-out and/or exchange with outside air having low working levels prior to a five minute working level measurement to decrease the measured working level significantly below the annual average for the structure. It is for this reason that the occupants are asked to close both windows and doors for eight (at least three) hours prior to the five-minute working level measurement. However, in order to tell whether the measured working level can be used to estimate the annual average, it is also necessary to have some method that can be used to determine whether the structure has in fact been closed up properly prior to measurement, or whether plate-out or exchange has been unusually rapid for some other reason.

The turnover time of the radon daughters in the air in a structure prior to a five-minute radon daughter measurement can be calcuiated from the degree of disequilibrium between the daughters ${ }^{218} \mathrm{Po},{ }^{214} \mathrm{~Pb}$ and ${ }^{214} \mathrm{Bi}$ using the following equations reported by Morken and Scott. (6)

6 Morken, D.A. and J. K. Scott, 1966. "The Effects on Mice of ContinuaT Exposure to Radon and its Decay Products on Dust." AEC Report $\underline{\text { UR-669-1966. }}$ 


$$
\begin{aligned}
& { }^{218_{\mathrm{P}_{0}}}=\frac{\left(222_{\mathrm{Rn}}\right) \lambda_{\mathrm{A}}}{\frac{F}{V}+\lambda_{A}} \\
& 214_{\mathrm{Pb}}=\frac{\left(218_{\mathrm{PO}_{0}}\right) \lambda_{\mathrm{B}}}{\frac{F}{V}+\lambda_{B}} \\
& 214_{\mathrm{Bi}}=\frac{\left(214_{\mathrm{Pb}_{\mathrm{D}}}\right) \lambda_{C}}{\frac{F}{V}+\lambda_{C}}
\end{aligned}
$$

Where

${ }^{222} \mathrm{Rn},{ }^{218} \mathrm{Po},{ }^{214} \mathrm{~Pb}$, and ${ }^{214} \mathrm{Bi}=$ Air concentration of these radionuclides $(p C i / /$ iteri

$\lambda_{A}, \lambda_{B}, \lambda_{C}=$ Radioactive decay constants of 218 Po, ${ }^{214} \mathrm{~Pb}$ and $274_{\mathrm{Bi}}$, respectiveiy $\left(\mathrm{min}^{-1}\right)$

$F=$ Continuous flow rate of clean, uncontaminated air into the structure (liters/min)

$V=$ Volume of air in the structure (liters)

And

$$
\frac{V}{F}=\text { Turnover time (minutes) }
$$

Equation 2 can be rearranged to give the turnover time as a function of ${ }^{210} \mathrm{Po}$ and ${ }^{214} \mathrm{~Pb}$ :

$$
\frac{V}{F}=\frac{214 P_{P b}}{\left(218 P_{0}-214 P_{P b}\right) \lambda_{B}}
$$

equation 3 can be rearranged to give the turnover time as a function of $214 \mathrm{~Pb}$ and ${ }^{214} \mathrm{Bi}$ :

$$
\frac{V}{F}=\frac{214_{B i}}{\left(214_{\mathrm{Pb}}-214_{\mathrm{Bi}}\right){ }^{\lambda} \mathrm{C}}
$$


and substitution of equation 2 in equation 3 gives the turnover time as a function of ${ }^{218} \mathrm{Po}$ and $214_{\mathrm{Bi}}$ :

$$
\frac{V}{F}=-\frac{2}{-\left(\lambda_{B}+\lambda_{C}\right)+\left[\left(\lambda_{B}+\lambda_{C}\right)^{2}-4 \lambda_{B} \lambda_{C}\left(1-\frac{21 P_{0}}{214_{B i}}\right)\right]^{1 / 2}}
$$

These equations are only approximate because they asslime (1) steady state, (2) complete mixing within the structure, and (3) negligible radon concentrations in the outside air. None of these assumptions is strictly true for a typical house, but the calculated turnover times do provide a useful parameter for identifying measurements that were made under conditions of rapid plate-out and/or air exchange.

The equations of Morken and Scott can be used to calculate the turnover time from the relative concentrations of any two of the three short-lived radon daughters, but in practice the turnover time is calculated from only the concentrations of the ${ }^{218} \mathrm{Po}_{0}-{ }^{214} \mathrm{Bi}$ pair and the ${ }^{214} \mathrm{~Pb}-{ }^{214} \mathrm{Bi}$ pair using equations 4 and 6 , respectively. Since ${ }^{218}$ po has on 1 y a three-minute halflife, the turnover time calculated from the concentrations of $218 \mathrm{Po}$ and ${ }^{214} \mathrm{Bi}$ (or ${ }^{218} \mathrm{Po}$ and ${ }^{214} \mathrm{~Pb}$ ) is sensitive to conditions just prior to the measurement, but the turnover time calculated from concentrations of the longer-1ived ${ }^{214} \mathrm{~Pb}$ and ${ }^{214} \mathrm{Bi}$ are sensitive to processes occurring over a longer time period. If the calculated turnover times are unusualiy short, plate-out or air exchange has been unusually rapid prior to measurement, suggesting that the measured radon daughter concentrations will tend to be uncharacteristically low. Under ordinary conditions the radon daughter activities decrease 
in the order ${ }^{218} \mathrm{Po} \geq 2^{214} \mathrm{~Pb} \geq 214 \mathrm{Bj}$. However, statistical fluctuations in the measurements and/or rapid variations in the plate-out rate (which is significantiy greater for ${ }^{218}$ Po than for either ${ }^{214} \mathrm{~Pb}$ or ${ }^{214} \mathrm{Bi}$ ) can result in changes in this order. The intermittent operation of a circulating heating system, for example, can cause rapid variations in the plate-out rate. If the measured concentrations of ${ }^{218} \mathrm{Po}$ and ${ }^{214} \mathrm{~Pb}$ become less than that of ${ }^{214} \mathrm{Bi}$, the calculated turnover times become negative. If the departure from equilibrium is slight, indicating that plate-out is slow, the calculated negative turnover time will be long. However, if the departure is large, indicating rapid plate-out, then the calculated negative turnover time will be short. Review of past measurements has shown that positive turnover times calculated from either pair of radon daughters were longer than 32 minutes $90 \%$ of the time if the wind speed was less than 8 mph (Figure 2). Inspection of the turnover times has also shown that negative turnover times shorter than 100 minutes result from significant departure from equilibrium. Therefore, it has been decided to consider radon daughter measurements to be invalid because of excessive plate-out and/or air exchange when either of the two calculated turnover times is positive and shorter than 32 minutes, or if either is negative and shorter than 100 minutes (unless the measured radon daughter concentration is $>0.033 \mathrm{WL}$, in which case the measurement is considered to be valid).

If the radon daughter measurement in a structure is considered to be invalid because of short calculated turnover times, the structure is scheduled for re-measurement at a later date. If both of the calculated turnover times for the re-measurement are 
FIGURE 2. FREQUENCY DISTRIBUTION OF RADON PROGENY TURNOVER TIMES IN RESIDENCES IN

EDGEMONT, S.D. BASED ON THE RATIO:

${ }^{214} \mathrm{~Pb} /{ }^{214} \mathrm{Bi}$

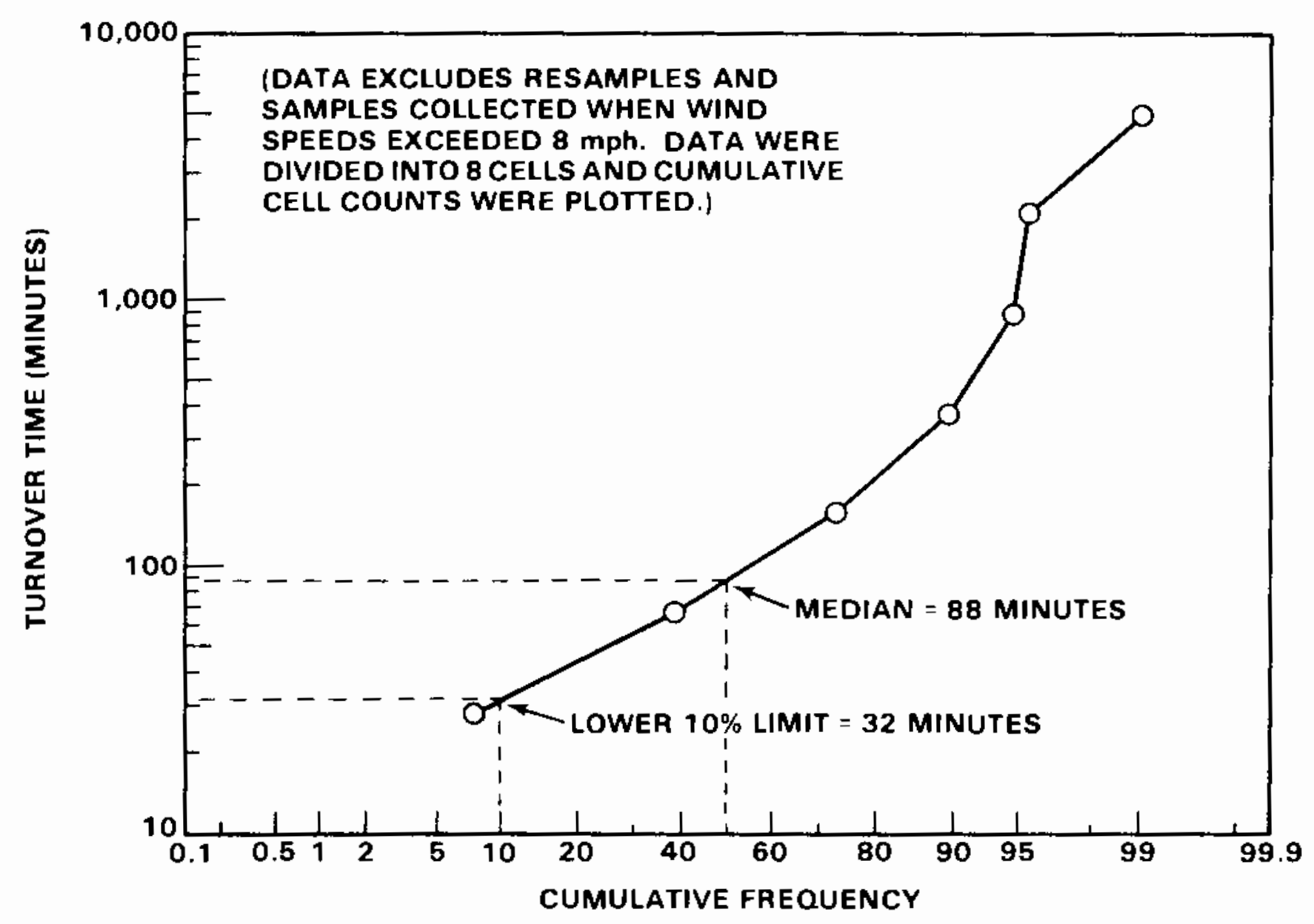


either positive and longer than 32 minutes, or negative and longer than 100 minutes, the re-measurement is accepted as valid and is reported. However, if the re-measurement also fails the turnover time criterion, it is considered that five-minute radon daughter measurements will not provide a sufficiently accurate estimate of the annual average working level, so the structure is scheduled for long-term radon daughter measurement. However, the measurement showing the longer turnover times will be considered to be the more representative of the annual average and will be reported as an interim value. It should be remembered that even if short turnover times are characteristic of a structure during the period of time that the five-minute measurements are made, future modification of the structure or the living habits of the occupants could lengthen the turnover time and cause the radon daughter concentrations to rise to unacceptable levels.

It has also been observed that there is a significant reduction in the number of measured working levels above $0.010 \mathrm{WL}$ when the wind speed was above $8 \mathrm{mph}$. Therefore, the wind speed is now checked each morning and an attempt is made to avoid sampling when it is above $8 \mathrm{mph}$.

d) Decision Levels

Working Levels $<0.01$ WL - If the structure average of the five minute working level measurements is less than $0.010 \mathrm{WL}$, and if the turnover times of the radon daughters for the measurements satisfy the criterion described above, the structure is considered to satisfy the radon progeny criterion for clearance from remedial action. 
Working Levels >0.033 WL - If the measured five-minute working level is greater than $0.033 \mathrm{WL}$ on either floor, a second measurement is made at a later time to confin the elevated concentrations. The valid measurements taken on each floor during the initial survey and during any repeat surveys are averaged floor by floor. (This is necessary since there may be more valid measurements available for one floor than for another.) The average for the structure is then calculated as the average of the individual floor averages. However, beginning on February 25, 1981, all indoor working levels above 0.010 WL measured on days when the outdoor working level is above $0.015 \mathrm{WL}$ shall be disregarded. The measurement will be repeated at a later date because the elevated indoor working levels could be due to outside air, and might not be characteristic of the structure. If the structure average is greater than $0.033 \mathrm{WL}$, the structure is considered to exceed the EPA annual average working level standard of $0.015 \mathrm{WL}$ and is immediately scheduled for engineering assessment.

Working Levels of 0.01 to $0.033 \mathrm{WL}$ - If the structure average of the valid working level measurement is between 0.01 and $0.033 \mathrm{WL}$, it is considered that grab samples will not provide an estimate of the average annual working level that is sufficiently accurate to provide a basis for a decision on remedial action. Therefore, the structure is scheduled for long-term radon progeny measurements, unless the structure or yard fails either of the other criteria for clearance from engineering assessment (e.g., indoor or outdoor gamma exposure rates $>20 \mu \mathrm{R} / \mathrm{hr}$ above background, ${ }^{226} \mathrm{Ra}>5 \mathrm{pCj} / \mathrm{g}$ in soil). In the latter case, the property is scheduled for engineering assessment without further radon daughter measurements. 


\section{Long-Term Radon Daughter Measurements}

\section{a) Introduction}

Where lang-term radon progeny measurements are required, the measurements are being made using RPISU and, in some cases, Track Etch, but the RPISU will be considered to be the standard instrument, at least until simultaneous measurements by RPISU and Track Etch have shown that Track Etch can provide annual average working levels that are of accuracy comparable to those provided by the RPISU.

The RPISU collects radon daughters on a filter, next to which is placed a thermoluminescent dosimeter (TLD) chip. An annealing process is later used to determine the total energy deposited in the chip by alpha particles produced by the decay of the radon daughters, ${ }^{218} \mathrm{Po}$ and ${ }^{214} \mathrm{Po}$. Track Etch devices consist of thin sheets of alpha sensitive material that are passively exposed to the atmosphere. Alpha particles from radon and radon daughters produce damage tracks in the sensitive material. These tracks are later made visible by a suitable etching technique, and then counted. Working levels are calculated using an assumption about the degree of equilibrium between radon and its daughters (usually 50\%).

The major advantages of the Track Etch devices are that they are small and require no pumps, electricity or any other associated hardware. Therefore, they can be exposed over long periods of time without maintenance. However, potential errors produced by the assumption of a constant degree of equilibrium may limit their accuracy, and could lead to bias in their results in individual structures. 


\section{b) Protocols}

Annual average working levels are determined from six 100-hour integrated RPISU measurements taken every other month during the course of a year on the main floor of each structure. The RPISUs have been provided by the EPA facility at Las Vegas. They a1so calibrate the TLD chips and analyze them after they have been exposed. PNL places the RPISUs in the structures to be measured and determines the air flow rate at the beginning and end of sampling using a rotometer supplied by the EPA. The flow rate is generaliy one to two liters/minute.

The filter on the RPISU tends to plug up, causing a pressure sensor to turn off the instrument. When this occurs before 100 hours have elapsed, the filter and TLD chip will be replaced (they come as a sealed unit) and the measurement continued until a total sampling time of 100 hours has been obtained. After each filter is changed, the running time meter is read to determine the number of hours of exposure. EPA has indicated that five working level liters is the smallest measureable sample. At a flow rate of one liter/ minute and a working level of $0.015 \mathrm{WL}$, it requires about five hours to obtain fjve working level-liters. Therefore, any TLD chip that is not exposed for at least five hours is not included as part of the 100-hour sample.

If the annual average working level calculated from six RPISU samples is greater than $0.015 \mathrm{WL}$, the structure is scheduled for engineering assessment, but if the average is less than or equal to 0.015 , the structure then satisfies the working level criterion for clearance from remedial action, since long-term measurements would not have been made if the property had not passed all of the other clearance criteria (e.g., gamma exposure rate less than $20 \mu R / h r$ 
above background and radium concentration in soil less than $5 \mathrm{pCi} / 9$ ). Terradex Type F Track Etch devices will also be placed in 50 structures in which RPISU measurements are being made to determine how well the working levels determined using Track Etch correspond to those measured with the RPISU. The Type F device consists of the alpha sensitive detector taped to the bottom (inside) of a plastic cup and protected from ambient radon daughters by a filter. It measures only radon (and daughters produced by the decay of radon inside the cup). Working levels are calculated assuming 50\% equilibrium with the measured radon concentration. This configuration avoids problems produced by the variability in the plate-out of radon daughters on the surfaces of the structure or of the detector caused by variations in atmospheric parameters such as humidity and aerosol concentration. One Track Etch witl be placed for a period of one year in each of the 50 structures, and another will be changed every other month in these structures at the same time as the RPISU is installed. If these measurements show that the Track Etch yields average annual working levels of comparable accuracy to those provided by the RPISU, then Track Etch will be used in the future to measure annual averages. 
c) Discussion of Radon Daughter Measurements

Question (Momeni, ANL): Doesn't sealing the homes for eight hours introduce a positive bias from the usual house occupant routine?

Answer (Jackson, PNL): $\quad$ It is necessary to make the radon daughter measurements under uniform sampling conditions so that a single correction factor can be used to derive annual average radon daughter working levels from the five minute measurements. It has been estimated $(7)$ that the annua 1 average will be 0.6 times the closed structure value.

Question (Kisieleski, ANL): How do you determine the representative place for sampling?

Answer (Jackson):

We sample the living room (or the family room if it is the main living area) and any habitable basement.

Question (Endres, HUD):

What is the objective of the survey with respect to eventual remedial action?

Answer (Eadie, NRC):

We are attempting to screen properties to locate residual radioactive material. The next phase is engineering assessment. We would get adequate information from the engineering assessment to determine the best way to reduce the radioactivity to acceptable levels.

A corment was made that NRC has no responsibility for doing anything about any "natural" radioactive material native to the site (even though such natural levels may exceed 40 CFR 192 limits).

Question (Momeni, ANL): Are you concerned that nighttime levels may be higher than daytime levels?

Answer (Jackson):

We suspect that the higher nighttime levels that have been observed in structures by several investigators are caused primarily by the lower ventilation rates that occur at night. Windows and doors are opened less often. Radon daughter concentrations measured during the day in a closed structure should be comparable to nighttime concentrations.

Question: Wouldn't monthly integrated measurements be different?

7 Letter from J. Geidt, U.S. Environmental Protection Agency, to J. Endres, U.S. Department of Housing and Urban Development, dated August 5, 1980. 
Answer (Jackson):

Answer (Jackson):

Question:

Answer (Jackson):

Question:

Answer (Jackson):
Question:

Yes, but the initial survey is a screening survey, and the screening limits have safety factors built into them. When the measured values are close to the EPA standard, the protocols call for long-term measurements.

At the same time and in the same vicinity, do you find indoor and outdoor working levels the same?

We have not made simultaneous outdoor and indoor measurements as yet. We have measured radon daughters at a single outdoor location once a day in the morning, and have frequently found natural outdoor concentrations above the EPA standard for indoor air.

Is your windspeed criterion for sampling an adequate criterion?

We believe it to be useful for determining when samples should not be collected.

Have you looked at correlation wi th barometric pressure?

We have not observed a consistent association between low results and rising barometric pressure, or between high results and falling barometric pressure. However, we have not studied the correlation, if any, in sufficient detail to establish whether there are subtle interactions.

(Some discussion and questions followed concerning outdoor "control" sampling and what influence the nature of the construction had on the observed working
levels.)

Question:

Do you find radon progeny in equilibrium with radon?

Answer (Jackson):

We have not yet measured indoor radon concentrations at the same time as radon daughter measurements were being made, because the standards are set for radon daughters, not radon.

Question:

What is the air sampling rate?

Answer (Jackson):

30 to 50 liters per minute.

Question:

Do you correct the volume for altitude? 
Answer (Jackson):

Question (Groelsema, DOE): He expressed concern about background working level measurements out of doors being taken at the PNL office location rather than the area of the structure being sampled.

Response (Jackson):

Question:

Answer (Jackson):

Question:

Answer (Jackson):

Question:

Comment:

Conment (Eadie, NRC):

Question:

Answer (Jackson):

A dry test meter is used for calibration. No correction is necessary for altitude.

We make a one-location measurement. The current standard includes background, so outdoor background measurements are not necessary unless the outdoor levels approach the indoor standard.

Wouldn't gamma radiation levels be better for screening?

We use working levels because of the criterion. We also make the gamma measurement.

What is an "anomalous level"?

Any reading that requires an engineering assessment. In the case of radon daughters, it is $>0.033 \mathrm{WL}$ for a five minute sample or $>0.015 \mathrm{WL}$ for a long-term measurement.

When trying to make decisions based on $0.01 \mathrm{WL}$, isn't this straining the ability to measure when we also take into account real ijfe fluctuations?

I tend to agree because even opening a door would change the concentration.

Conditions during sample collection are standardized as much as possible to minimize variations.

I am concerned with Radon Progeny Integrating Sampling Unit (RPISU) and correlation with other methods.

We are looking at the correlation between the five minute measurements and the RPISU measurements that have been made by EPA in Edgemont. Some data will be presented later.

Comment (Kisjeleski, ANL): I wonder if we know well enough the impact of the decisions being made from the measurements. Probably the approach is too simplistic. Such things as building materials of the home, ventilation, etc., are not accounted for. 
Answer (Jackson):

Comment (Bernhardt, EPA LV):

Coment (Momeni, ANL):

Response (Jackson):

Comment (Endres, HUD):

Comment (Groe]sema, DOE):

Corment (Jackson):
Yes, but this is a screening effort designed primarily to identify structures that clearly require either engineering assessment or longterm measurements.

Mr. Bernhardt called attention to the relationship between condensation nuclei and working levels in a building. He discussed data showing large variations in working levels in a home which presumably were related to the presence or absence of condensation nuclei. Data were also shown which indicated reductions in the working level after operation of central-air fans. Short-term (tens of minutes) operations of central-air fans can reduce the working level by more than a factor of two. The radon progeny equilibrium fraction in air is dependent on the condensation nuclei and the air turnover rate in air-conditioning (heating or cooling) systems.

Combined measurement errors are $\pm 100 \%$ for such grab working level measurements.

Not so. The repeatability of the measurements made when the initial measurement exceeded 0.033 WL was $\pm 25 \%$ relative standard deviation. The sources of error other than counting statistics are relatively small, approximately 5-10\%. of course, the radon daughter concentrations themselves vary with conditions.

We might release a home with a working level that was marginally higher than the current guidelines, if the circumstances seemed to warrant it. This would be an attempt to protect a property owner from the refusal of Federal mortgage insurance because of a measurement error or inaccuracy.

He called attention to Keith Schiager's review(8) of measurement data at Grand Junction. Schiager evaluated several radon and radon progeny methods. This important report is to be issued soon by the DOE. Schiager's report concludes that grab samples were suspect because of changes in concentration in time and space.

We must look at the sampling conditions for the grab samples Schiager analyzed. Was the barometer steady, the house closed, the wind $<8 \mathrm{mph}$, etc.?

8 Schiager, K. J., JuTy 11, 1980. "Analys is of Currently Approved and Proposed Procedures for Establishing Eligibility for Remedial Action. " Oraft report prepared for the U. S. Department of Energy. 
Comment (Langner, $\mathrm{CDH}$ ):

Question (Scarano, NRC):

Answer:

Comment (Scarano, NRC)

Question:

Answer (Jackson):

Comment (Scarano, NRC):

Comment (Endres, HUD):

Comment (Groeisema, DOE):

Comment (Haywood, ORNL):

Comment:
He thought that the Grand Junction data were collected with restrictions similar to those used by PNL in Edgemont. However, season might make a difference -- the winter versus surnmer, etc.

What were the criteria for selecting houses surveyed at Grand Junction?

Sites were picked that were suspected or known to have tailings nearby.

At Edgemont we have no prior indication that tajings are involved at any given location. This is a screening survey of all properties.

Have available Ford, Bacon and Davis Utah Inc. and EPA data been used?

Yes. ${ }^{(8)}$ We use them to evaluate our surveys.

One of our needs is to determine levels of concern to HUD in guaranteeing mortgage loans on property. HUD has determined that radon daughter concentrations less than 0.02 weighted working levels (WWL) would be acceptable. Our methods are constrained by HUD requirements.

If the working level is greater than the limit, remedial action is required before we can accept the property for HUD financing. We are looking to EPA for better guides.

At Grand Junction, we are Tooking for houses eligible for remedial action, and those ineligible. People want remedial action to be performed. A different point of view exists at Edgemont. Property owners primarily want HUD clearance so that they can obtain federally guaranteed financing.

I would recommend radon rather than radon daughter measurements for the initial screening tests.

Several other investigators also expressed a preference for radon measurements.

9 Ford, Bacon \& Davis Utah Inc., May 1978. "Engineering Assessment of Inactive Uranium Mill Tailings - Edgemont Site, Edgemont, South Dakota." Prepared for U. S. Nuclear Regulatory Commission. 
5. Indoor Gamina Surveys

a) Introduction

According to 40 CFR 192, remedial action is required if residual radioactivity results in indoor gamma radiation exposure $>20$ microroentgens per hour $(\mu \mathrm{R} / \mathrm{hr})$ above background. In an earlier survey, the EPA determined that the outdoor gamma exposure rate at Edgemont averaged $13.2 \mu \mathrm{R} / \mathrm{hr}$ at locations not influenced by residual radioactivity, and that about $95 \%$ of these locations had average gamma levels less than $14.5 \mu \mathrm{R} / \mathrm{hr}$. Therefore, $14.5 \mu \mathrm{R} / \mathrm{hr}$ was chosen as the background at Edgemont, so that only about $5 \%$ of the property will exceed this background as a result of natural radioactivity. Our measurements at Edgemont have yielded average outdoor background levels very close to those reported by EPA. In any event, in most cases where residual radioactivity is present, gamma exposure rates much greater than $20 \mu \mathrm{R} / \mathrm{hr}$ above background are observed, so the exact value chosen for the background has relatively little effect on the decision as to whether engineering assessment is required.

b) Protocols

Indoor gamma surveys are made of all habitable floors and basements using gamma survey meters. The survey meters being used at Edgemont are Ludlum micro-R-scintillometers that employ sodium iodide crystals for gama detection. These instruments are compared at least once a day to a calibrated Reuter-Stokes (Model S-111) pressurized ionization chamber on the ground floor of homes. The pressurized ionization chamber sensitivity is checked with a reference source daily. All instruments were calibrated at PNL prior to use and are periodically returned to PNL for recalibration. All pressurized ion chamber readings taken in the field are corrected

10 Thrall, J.E., Hans, J.M., Jr. and Kallemeyn, V., "Above Ground Gamma Ray Logging of Edgemont, South Dakota and Vicinity," U.S. EPA Technical Note ORP-LY-80-2, February, 1980. 
to the standardized laboratory calibration. Micro-R-meter readings are corrected to equivalent pressurized jonization chamber readings using the ratios determined in the field on the day of measurement. Indoor gamma measurements are made at an elevation of about three feet at the grid points (approximately overy 5 feet) of a $25 \mathrm{ft}^{2}$ grid starting at one wal1. Measurements are also made at the far wall (unless this point is within a couple of feet of another measurement, such as in another room). The measurements are made with the survey meter set on slow response (long time constant). Readings are not taken until the needie has stabilized for a few seconds. The corrected readings are recorded on a detailed drawing of the floor plan of the structure that is drawn based on measurements taken using a tape measure (Figure 3). If none of the readings is greater than $14.5 \mu \mathrm{R} / \mathrm{hr}$, the structure is considered to pass the gamma radiation criterion for clearance. However, if readings above $14.5 \mathrm{\mu R} / \mathrm{hr}$ are encountered, or if the meter shows a pronounced increase in the exposure rate at any location, a search is made for elevated readings in contact with surfaces of the structure. If a corrected contact reading greater than $20 \mu \mathrm{R} / \mathrm{hr}$ background is observed, this reading is recorded. The contact reading is recorded beneath a line drawn under the surface reading. Unless the object causing the elevated ganna reading can be disposed of (e.g., small rocks, radium dial clock), the structure is considered to fail the gamma criterion and is scheduled for engineering assessment.

It should be stressed that the primary purpose of the gamma survey is to locate any deposits of residual radioactivity. Therefore, the detector output is observed carefuliy, and any suspicious changes in the meter reading are followed up to insure that no deposits 
FIGURE 3. ILLUSTRATION OF INDOOR GAMMA SURVEY

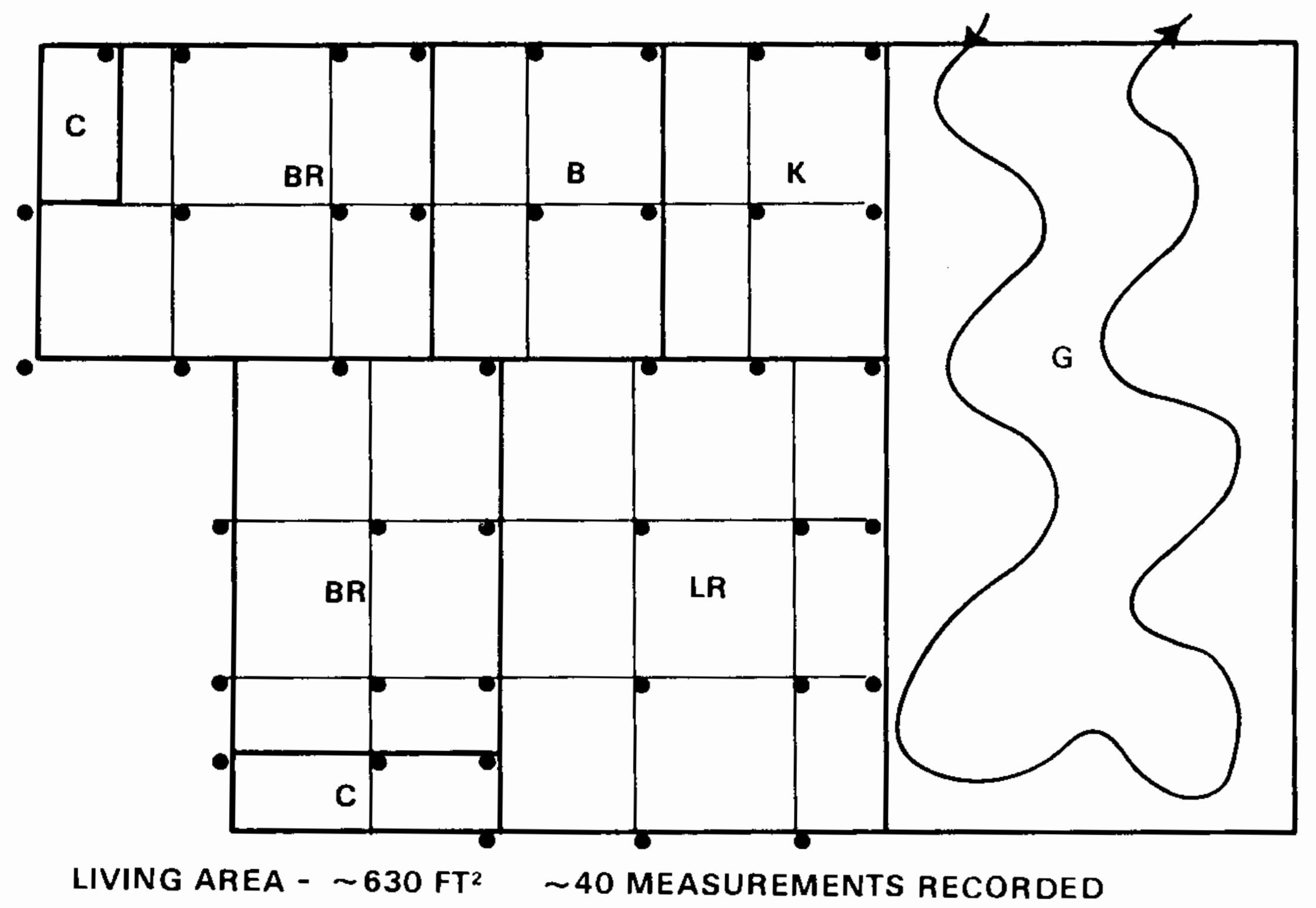

GARAGE - MAXIMUM AND ESTIMATED AVERAGE MEASUREMENTS RECORDED 
anywhere inside the structure are missed. The grid measurements serve as a record that a detailed survey has been made.

The Ludlum scintillometer is equipped with an audible signal that clicks at a rate proportional to the gamma exposure rate. Prior to the January 1981 workshop, the audible signal was not used because it does not provide a numerical signal, and because its clicking might cause the owner or neighbor to fear that his building was highly radioactive. However, the clicker does have the advantage that it provides a faster response than does the meter, so it might detect small amounts of residual radioactivity between grid points that the meter would not detect. At the workshop, it was suggested that the clicker has proven very useful for locating residual activity during surveys at other locations. Therefore, following the workshop the Ludium scintillometers were fitted with earphones that will enable the surveyor to hear the clicker without disturbing the property owner. In the future, the earphones will be used in addition to the meter reading to locate residual radioactivity during both indoors and outdoors surveys.

\section{Gamna Surveys in Garages and Nonhabitable Basements}

\section{a. Protocols}

Prior to the January 1981 workshop, gamma levels in garages and nonhabitable basements were measured at an elevation of about three feet with a Ludlum scintillometer set on fast response during a slow, serpentine walk through (Figure 3). Brief stops were made to allow the meter to stabilize. If readings greater than 14.5 $\$ \mathrm{R} / \mathrm{hr}$ were encountered, or if the reading showed a significant increase at any location, a search was made for elevated contact readings. If contact readings greater than $20 \mu \mathrm{R} / \mathrm{hr}$ above background were observed, the building was scheduled for engineering 
assessment. As a result of discussions at the workshop, gamma surveys in garages and nonhabitable basements are now being conducted using a $25 \mathrm{ft}^{2}$ grid and measurement procedures identical to those described in the previous section inside other structures.

\section{b) Discussion of Indoor Gamra Surveys}

Comment (Wynveen, ANL): Wynveen made a strong recommendation for using earphones with the $\mu \mathrm{R}$ meter surveys.

Comment

Other participants recommended surface measurements as being better for surveys than measurements taken at 3 feet. (PNL includes surface surveys as well when indicated by elevated measurements at 3 feet.

7. Outdoor Gamma Surveys of Land with Structures

a) Introduction

According to 40 CRF 192, remedial action is required if residual radioactivity results in average ${ }^{226} \mathrm{Ra}$ concentrations in soil $>5 \mathrm{pCi} / \mathrm{g}$ in any $5 \mathrm{~cm}$ thickness within one fuot of the surface, or any $15 \mathrm{~cm}$ thickness below one foot. Outdoor gamma radiation surveys are being conducted for the purpose of identifying locations where soil sampies should be collected and analyzed because they are likely to contain the highest ${ }^{226} \mathrm{Ra}$ concentrations present at that property.

b) Protocols

Gamma measurements are made at an elevation of about three feet using Lud] um micro-R-meters (Model 12S) set at slow response at the grid points (approximately every seven feet) of a $50 \mathrm{ft}^{2}$ square grid in the yards adjoining homes. Readings are not taken until the meter has stabilized for a few seconds. The corrected readings are recorded on a drawing of the yard made using a tape measure (Figure 4). The house and other structures are shown on the drawing. 
FIGURE 4. ILLUSTRATION OF AN OUTDOOR

\section{GAMMA SURVEY}

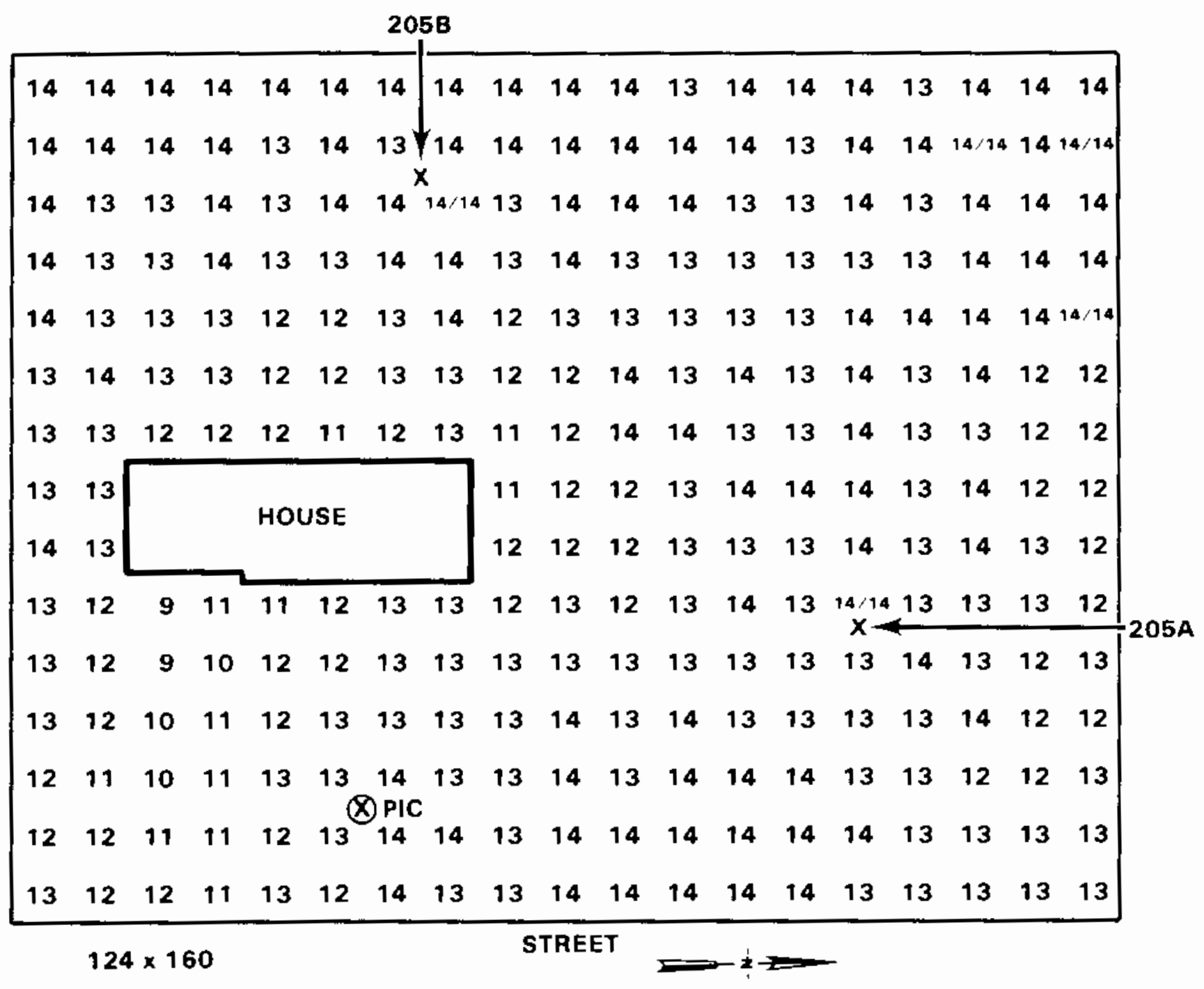


To save time, the distances between grid points are paced off, rather than measured. In the event that a lot is exceedingly large, only that portion which is within 50 feet of the structure(s) is surveyed using the $50 \mathrm{ft}^{2}$ square grid. The rest is surveyed using the procedures described below for open land. The Ludlum scintillometers are cross-calibrated at least once a day with a pressurized ionization chamber at a location that is to be surveyed. All Ludlum readings are corrected to the equivalent pressurized ion chamber reading before being recorded on the survey map. Gamma Radiation Levels $<14.5 \mu \mathrm{R} / \mathrm{hr}$ - If no corrected gamma exposure rates greater than $14.5 \mu \mathrm{R} / \mathrm{hr}$ (including background) are observed at the three-foot elevation, surface soil samples are collected for ${ }^{226} \mathrm{Ra}$ analysis at any two locations showing the highest readings, and contact readings are recorded at these locations. In the event that it is impractical to collect a surface sample at a location of maximum reading (e.g., because of the presence of pavement or valuable shrubs) an alternate location showing a high reading is sampled.

Gamma Radiation Levels $>14.5 \mu \mathrm{R} / \mathrm{hr}$, but no Surface Anomalies If corrected gamma exposure rates greater than $14.5 \mu \mathrm{R} / \mathrm{hr}$ (including background) are observed at the three foot elevation, or if the readings show a significant increase at any location, a search is made for elevated readings at the surface, and contact readings are recorded on the drawing of the property (a line is drawn beneath the three-foot reading, and the contact reading is entered below the line). However, if the three-foot readings are consistently greater than $14.5 \mu \mathrm{R} / \mathrm{hr}$, but no garma anomalies are observed during the first two surface searches, no more surface searches are conducted unless a three-foot elevation reading shows an increase of 
one $\mu \mathrm{R} / \mathrm{hr}$ or more. Surface soil samples are taken for ${ }^{226} \mathrm{Ra}$ analys is at two locations showing maximurn gamma readings. Contact Gamma Radiation Levels $>20 \mu R / h r$ Above Background - If surface gamma readings greater than $20 \mu \mathrm{R} / \mathrm{hr}$ above the $14.5 \mu \mathrm{R} / \mathrm{hr}$ background are observed, up to five or six surface and core soil samples are collected for ${ }^{226} \mathrm{Ra}$ analysis at locations of maximum gamma exposure rates. The property is scheduled for a more detai]ed engineering assessment because it is assumed that material containing greater than $5 \mathrm{pCi} / \mathrm{g}$ of ${ }^{226} \mathrm{Ra}$ is present, even if the initial soil samples collected happened to miss it.

\section{Gamma Surveys of Open Land}

\section{a) Introduction}

According to 40 CFR 192, remedial action is required on open land if residual radjoactivity results in ${ }^{226} \mathrm{Ra}$ concentrations in soil $>5 \mathrm{pCi} / \mathrm{g}$ in any $5 \mathrm{~cm}$ thickness within one foot of the surface, or any $15 \mathrm{~cm}$ thickness below one foot. However, the land is also ineligible for HUD federally guaranteed financing if the estimated average gamma radiation exposure rate, including background, is greater than $14.5 \mu \mathrm{R} / \mathrm{hr}$. Outdoor gamma radiation surveys are therefore conducted on open land to locate any soil containing greater than 5 $\mathrm{pCi} / \mathrm{g}$ of ${ }^{226} \mathrm{Ra}$ and to determine the average gamma radiation exposure rate of the property.

b) Protocols

Open lots are divided into grids containing four survey blocks along the shorter dimension and five survey blocks along the longer dimension of the property (Figure 5). On very large lots extra rows of survey blocks are added to keep the maximum distance between measurements below $200 \mathrm{ft}$. Extra blocks may be added to 
FIGURE 5. GAMMA SURVEY GRID FOR LOTS WITHOUT STRUCTURES

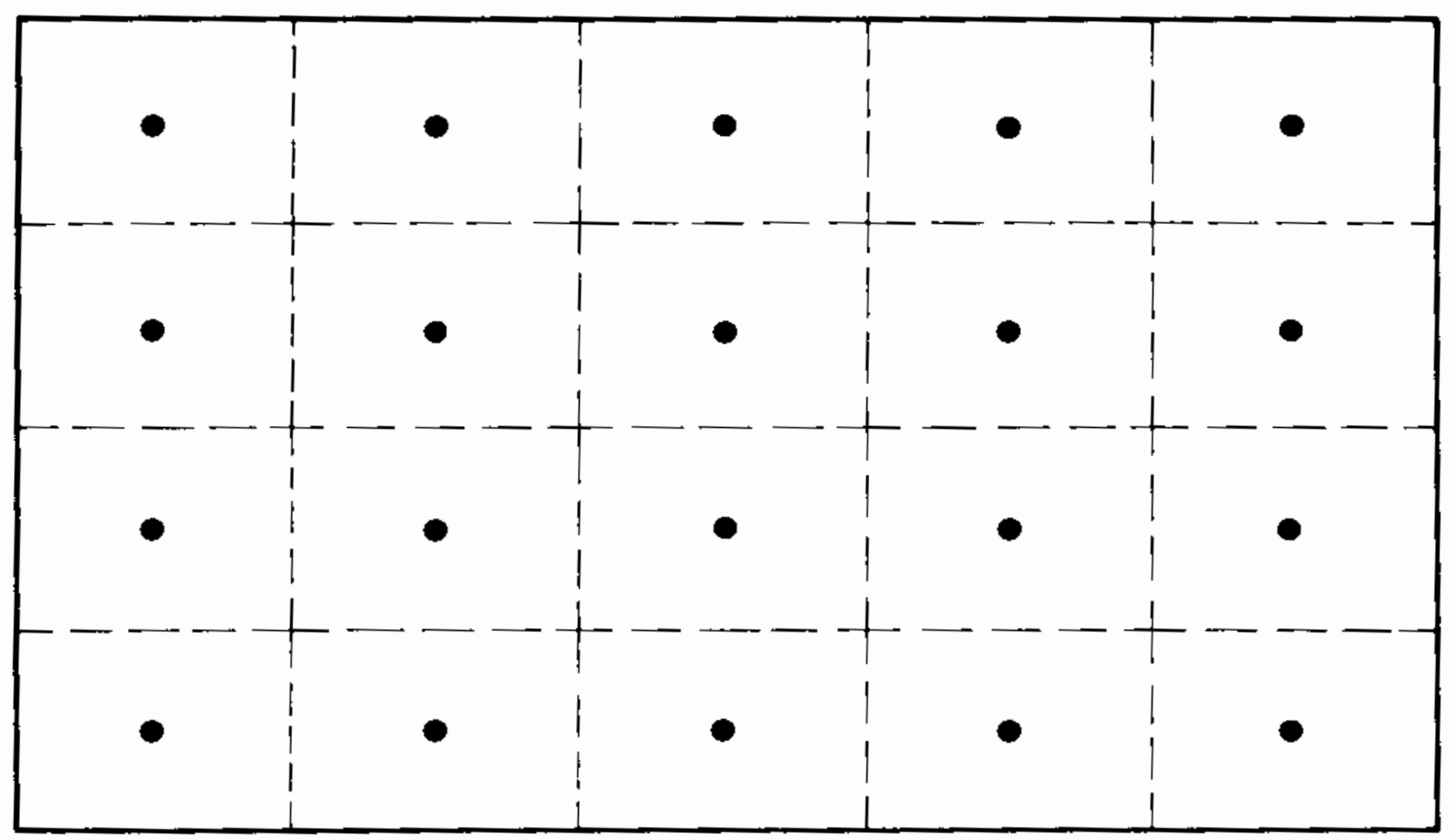

- MEASUREMENT POINTS 
irregularly shaped lots where the rectangular grid leaves unsampled areas. Gamma exposure rates are measured at an elevation of about three feet at the approximate center of each survey block with Ludlum scintillometers set on slow response. Readings are not recorded until the meter has stabilized for a few seconds. The scintillometers are compared to a calibrated Reuter-Stokes pressurized ionization chamber at one location on each lot, and a correction table prepared for each instrument. The corrected gamma readings are recorded on a drawing of the lot. A serpentine walk-through between each row of sampling locations is also made with the scintillometers set on fast response. The highest reading is recorded. The average gamma exposure rate for the property is calculated from the grid center measurements. Gamma Radiation Levels $<14.5 \mu \mathrm{R} / \mathrm{hr}$ - If no corrected gamma readings greater than $14.5 \mu \mathrm{R} / \mathrm{hr}$ (including background) are observed at the three foot elevation, one surface soil sample is collected for ${ }^{226}$ Ra anaiysis at a location of maximum gamma exposure rate. Gamma Radiation Levels $>34.5 \mu \mathrm{R} / \mathrm{hr}$, but no Surface Anomalies If gamma radiation levels greater than $14.5 \mu \mathrm{R} / \mathrm{hr}$ (including background) are observed at the three-foot elevation, or if the readings show a significant increase at any location, a search is made for elevated readings at the surface, and maximum contact readings are recorded on the drawing of the property. However, if consistent gamina readings about $14.5 \mu \mathrm{R} / \mathrm{hr}$ are observed at the three foot elevation, and no contact gamua readings greater than $20 \mu \mathrm{R} / \mathrm{hr}$ above the $14.5 \mu \mathrm{R} / \mathrm{hr}$ background are observed during the first two surface surveys, no more surface surveys are conducted unless the three-foot elevation reading shows an increase of one $\mu \mathrm{R} / \mathrm{hr}$ or 
more at another location. If no contact reading greater than 20 $\mu \mathrm{R} / \mathrm{hr}$ above background is observed at any location, one surface soil sample is collected for ${ }^{226}$ Ra analysis at a location of maximum gamma exposure rate.

Contact Gamma Radiation Levels $>20 \mu \mathrm{R} / \mathrm{hr}$ Above Background - If gamma radiation levels greater than $20 \mu R / h r$ above the $14.5 \mu R / h r$ background are observed at the surface, surface and core soil samples are collected for ${ }^{226} \mathrm{Ra}$ analysis at those locations. The property is scheduled for engineering assessment because it is assumed that material containing greater than $5 \mathrm{pCi} / \mathrm{g}$ of ${ }^{226} \mathrm{Ra}$ is present, even if it happened to be missed during initial soil sampling.

c) Discussion of Outdoor Gamma Surveys Question: What is PNL's basis for selecting a $7^{\prime} \times 7^{\prime}$ grid spacing? At Grand Junction a $10^{\prime} \times 10^{\prime}$ grid was used.

Answer (Young, We want to be sure to get good representation PNL):

$$
\begin{aligned}
& \text { of the surface, especially in the vicinity } \\
& \text { of structures. It was felt that there would } \\
& \text { be a significantly greater possibility of } \\
& \text { missing small amounts of residual radioactivity } \\
& \text { with a } 10^{\circ} \times 10^{\prime} \text { grid than with a } 7^{\prime} \times 7^{\prime} \text { grid. }
\end{aligned}
$$

A discussion ensued about possible "over-ki11." Are we doing too much (or too little)? A question was raised and some discussion followed on surface versus underground sources of gamma emitters. PNL does some coring to $46 \mathrm{~cm}$ when there is an indication of buried tailings suggested by higher than background radiation levels. (Some of those present had experiences in being "surprised" with buried radioactive material and were sensitive to the need to explore below the surface. Since soil sampling was to be discussed in the presentation on ${ }^{226}$ Ra measurements, the discussion was terminated.) 


\section{Soil Sampling Procedures}

\section{a) Surface Samples}

The soil sampling procedures at Edgemont have changed with time. Before January of 1981 , surface samples approximately $15 \mathrm{~cm}$ wide by $10 \mathrm{~cm}$ long by $8 \mathrm{~cm}$ deep were taken with a shovel with about a $15 \mathrm{crn}$ wide blade. Beginning in January of $198 \mathrm{I}$ surface samples are being collected, whenever possible, using a sampling device that samples a $200 \mathrm{~cm}^{2}$ area to a depth of $5 \mathrm{~cm}$. The device is driven into the ground and a small trench is dug next to each end of the sampler (preserving any grass sod for later replacement) to allow guiliotine-type blades to be inserted into both ends of the sampler at the $5 \mathrm{~cm}$ depth to enclose the sample. However, this sampler does not work properly in frozen or very rocky ground, so in these cases a shovel is still used to collect soil samples, but the depth is kept to less than $5 \mathrm{~cm}$. The surface samples are transferred to a plastic bag and shaken to separate the soil from leaves and grass, which are then replaced in the hole. If an insufficient soil sample remains, an adjacent surface sample is combined with the first sample.

b) Core Samples

Core samples are taken with a $3.8 \mathrm{~cm}$ diameter split tube corer that is driven into the ground to a depth of $46 \mathrm{~cm}$. Before March of 1981 the entire core was homogenized to form a single sample. Beginning in March of 1981 the top foot of the core is being divided into five samples, each about $5 \mathrm{~cm}$ in length, with the remain$15 \mathrm{~cm}$ of core forming a sixth sample. If necessary, the coring procedure is repeated at about the same location, combining samples from equal depths, until sufficient sample is obtained for analysis. 
This latter procedure has been developed to conform to the criterion proposed in 40 CFR 192 for ${ }^{226} \mathrm{Ra}$ concentrations in soil.

c) Procedure for the Analysis of Soil for ${ }^{226} \mathrm{Ra}$

Each soil sample is homogenized, weighed and transferred to a metal can with about a $410 \mathrm{ml}$ capacity. The cans are then sealed with a inanually operated sealer. They are checked for leaks by immersing in nearly boiling water and inspecting for bubbles. The cans are stored for at least 10 days, and usually considerably longer, to allow radon and its short-lived daughter, ${ }^{214} \mathrm{Bi}$, to grow in. The cans are then placed in plastic bags and the ${ }^{214} \mathrm{Bi}$ is counted for 10 minutes in a $23 \mathrm{~cm}$ diameter by $23 \mathrm{~cm}$ deep $\mathrm{NaI}(\mathrm{TI})$ well counter. The cans used are the largest that will fit into the well. The gamina-ray spectra are stored in a multichannel analyzer. The efficiency of the detector is determined daily by counting a homogenized uranium mill tailings sample whose ${ }^{226} \mathrm{Ra}$ concentration has been established by comparison with an NBS ${ }^{226}$ Ra standard. The background is determined daily by counting a can filled with distilled water. The ${ }^{226} \mathrm{Ra}$ concentrations are calculated from the measured ${ }^{214} \mathrm{Bi}$, after correcting for the fractional ingrowth of radon from the parent ${ }^{226} \mathrm{Ra}$ during the time between sampling and counting. In making this correction, it is assumed that the radon concentration was $50 \%$ of equilibrium with ${ }^{226}$ Ra at the time the can was sealed. Ten days after the can is sealed, the radon will be at $92 \%$ of equilibrium using this assumption, versus $84 \%$ if the radon concentration was zero at the time of sealing. Since most cans are allowed to sit considerably longer than 10 days before counting, the assumption of $50 \%$ equilibrium at the time of can sealing introduces little error. 
If any soil sample from a property contains greater than $5 \mathrm{pCi} / \mathrm{g}$ of ${ }^{226} \mathrm{Ra}$, that property is scheduled for engineering assessment. However, remedial action will not be undertaken if the ${ }^{226} \mathrm{Ra}$ is not due to residual radioactive materials, although for those cases the engineering assessment will still provide the property owners with an indication of the recommended procedures they may use at their own expense to remedy the problem. Therefore, soil samples that are shown by $\mathrm{NaI}(T)$ analysis to contain greater than $5 \mathrm{pCi} / \mathrm{g}$ of ${ }^{226} \mathrm{Ra}$ are shipped to PNL at Richland, Washington. There they are opened, homogenized, dried, re-weighed, and then counted on an intrinsic germanium gamma-ray spectrometer system. These analyses indicate (from the ratios of ${ }^{234} \mathrm{Th}$ to ${ }^{230} \mathrm{Th},{ }^{226} \mathrm{Ra}$ and $210 \mathrm{~Pb}$ ) whether the ${ }^{226} \mathrm{Ra}$ is due to residual radioactivity or to natural terrestrial radioactivity. The activity of ${ }^{234} \mathrm{Th}$, the 24-day half-life daughter of $238 \mathrm{U}$, should be much lower than the activities of ${ }^{230} \mathrm{Th},{ }^{226} \mathrm{Ra}$ and $210_{\mathrm{Pb}}$ in residual radioactivity from mill tailings, but should be nearly equal to the activities of these radionuclides in uranium ore, whether it is from a natural deposit or has been transported from a mining or milling site. (The concentrations of ${ }^{234} \mathrm{Th},{ }^{230} \mathrm{Th},{ }^{226} \mathrm{Ra}$ and $210 \mathrm{~Pb}$ are established by comparison to standards traceable to NBS or IAEA.) The resolution of the NaI(T1) is not adequate to measure the concentrations of these radionuclides, so it cannot be used to determine whether the ${ }^{226} \mathrm{Ra}$ is due to residual radioactivity. However, its higher sensitivity permits a much more rapid screening of samples than would be possible using a germanium diode. 
Visual observations of the physical characteristics of the soil samples and the deposits of the sampling sites are also used to indicate whether residual radioactivity is present. This is especially needed to differentiate between translocated ore (which is considered to be residual radioactivity) and ore in a natural, undisturbed deposit (which is not considered to be residual radioactivity). 
d) Discussion of Soil Sampling

Question:

Answer (Jackson, PNL):

Question:

Answer (Jackson):

Question:

Answer (Jackson):

Question:

Answer (Jackson):

Question:

Answer (Jackson):

Question:

Answer (Jackson):

Question:

Answer (Jackson):

Question:

Answer (Jackson):
What $y$ channels do you use?

The $1.76 \mathrm{MeV}{ }^{214} \mathrm{Bi}$ energy window is 1.62 to $2.32 \mathrm{MeV}$.

Would you always use the NaI detector?

I would use the NaI because its high efficiency leads to short counting times and lower analysis costs.

Is germanium better for the analysis of radium?

Yes, but the counting time is longer; it occupies too much time. We use the NaI counter to screen out the samples that do not require analys is using germanium diodes.

Were the samples dried?

Not for the NaI measurement, but for the germanium diode measurement the sample is dried, mixed, and pressed into a wafer.

Does the use of an "as is" sample of NaI analysis and a dried sample for germanium diode analysis lead to a discrepancy?

We measure the moisture loss in drying the samples, so that we can correct to the "as sampled" values. In any case, the absolute concentrations obtained from the germanium diode analysis are not as important as the concentration ratios.

Does everyone agree that the criterion of $5 \mathrm{pCi} / \mathrm{g}$ is to be that above background?

We interpret this limit to be $5 \mathrm{pCi} / \mathrm{g}$ above the level in undisturbed or free of tailings Tand.

Do you consider the amount you find as being above background even if it is $5 \mathrm{pCi} / \mathrm{g}$ ?

This is a screening survey and we are looking at absolute levels first, not relative to "background".

Even if first measurements are indicative of tailings or ore?

Yes. 
Question:

Answer (Jackson):

Corment:

Question:

Answer (Bernhardt, EPA):

Comment (Overmyer, FBDU):

Question:

Answer (Jackson):

Question (Groelsema, DDE):

Answer (Jackson):

Comment (Eadie, NRC):

Question:

Answer (Jackson, PNL):
Do you interpret the $5 \mathrm{pCi} / \mathrm{g}$ to be applied to soil as it comes from the ground?

Yes, as is. The moisture content at the time of sampling is not corrected for.

EPA does not intend to impose unreasonable procedures. If using wet samples is better, do it wet. Don't nit-pick. The Middlesex survey in which many instruments were used gave radium precision of $\pm 40 \%$. EPA says it is not necessary to get below $5 \mathrm{pCj} / \mathrm{g}$ even if $\pm 40 \%$ is the best one can do. Their limit is based upon practical measurement techniques used by competent scientists. The standards are low enough to allow for measurement uncertainties.

What is EPA's interpretation of the $5 \mathrm{pCi} / \mathrm{g}$ limit when applied to mill tailings remedial action?

When you have residual radioactivity present, the total radium concentration must be below $5 \mathrm{pCi} / \mathrm{g}$, even if natural radioactivity is also present.

If radium has leached into soil from a nearby tailings deposit, that soil must be cleaned up.

was a geologist really needed for the PNL surveys?

It was fortuitous that PNL had a geologist avai]able. He was able to determine if there was any likelihood of having uranium mineralization in areas in question, and was exceptionally accurate in identifying ore and tailings material.

Would you discuss the rationale for your sampling and measurement procedures for determining whether the standard was met or exceeded.

Our survey is a screening survey that attempts to locate maximum radium concentrations in surface soil (46 cm cores are also taken at locations of surface anomalies). If the radium concentration in the soil is greater than $5 \mathrm{pCi} / \mathrm{g}$, the core measurement will be used to aid the engineering assessment.

Routine coring to depth is to be avoided as a practical matter.

How much better is coring? How much more is revealed?

Coring has shown increases in radioactive material with depth at other sites. 
Question (Denham, PNL):

Answer (Perkins, PNL):

Question:

Answer (Jackson):

Question:

Answer (Jackson):

Question (Haywood, ORNL):

Answer (Jackson):

Question:

Answer (Jackson):

Comment:

Question:

Answer:

Question:

Answer (Jackson):
Were the objectives and methods clearly defined before the start of the progran?

of course we had an initial protocol and general methodology, but detailed design was not feasible with assurance until survey data were obtained. We are still trying to optimize our methodology.

Does it make a difference whether we err on the high side or low side?

This is a screening study. There are tests which can be applied eventualiy to get percentages of false positives and false negatives.

Do you always have people approach PNL to get surveyed?

Initially people came to us with requests. However, not all responded. Therefore, the State sent a letter to those that didn't. Later a second letter was sent by the City of Edgemont.

Were all the anomalies found in EPA surveys discovered in PNL survey?

We have not worked up all the data. We have seen cases where each survey found anomalies that the other did not. However, most of the anomalies measured by EPA, but not PNL, were small and some of them had been removed since the EPA survey.

In retrospect, do you believe that more intensive measurements would have been worth the effort?

This determination has not been made. It is not really possible without making the more extensive measurements.

Bentonite clay has high ganma. Some houses with clay under the house could show anomalous gamma.

Well water having high radium concentration is used for watering. Could this have resulted in high levels?

Water from that well is no longer used.

Engineering assessment..... What is it?

Bore hole logging, core sampling, and more extensive surveys are used to prepare a map of the radioactive material with depth. A plan is worked up for its removal. 
Question:

Answer (Jackson):
How does PNL do bore hole logging?

We have a germanium diode contained in a cryostat case which we lower into the hole. 


\section{RESULTS OF RADIATION SURVEYS AT EDGEMONT}

\section{Statistical Suminary}

Tables 1 and 2 report the number of residences and open lots that had been surveyed at Edgemont as of January 21, 1981. There are 658 residence units in Edgemont and vicinity. A residence unit is defined as a structure or part of a structure that may house one family or business and is located on the ground floor or basement. For example, each unit in a motel is considered to be a residence unit. A duplex consists of two residence units if they are on the ground floor or basement, but only the ground floor is considered to be a residence unit if the duplex is two-story. Before PNL. began its survey, 159 of these units had been surveyed for working levels by the State of South Dakota, and engineering assessment had been performed on 17 units by A.R.I.X., a private company. PNL has tested 277 additional residence units. The owners and/or occupants have refused to allow 16 units to be tested, and 160 others had not requested testing as of January 1,1981 . This leaves only 57 units that have requested testing, but have not yet been surveyed by PNL. However, in January the State of South Dakota sent a letter to residents of units that have not requested testing, pointing out that these units would have to be surveyed and cleared from remedial action before they could obtain HUD federally guaranteed financing, and that if they did not participate at this time they might have to pay for any subsequent survey or remedial action. As a result, several requests have been received recent]y. 
TABLE 1. STATISTICAL SUMMARY OF RESIDENCE UNITS IN EDGEMONT AND VICINITY

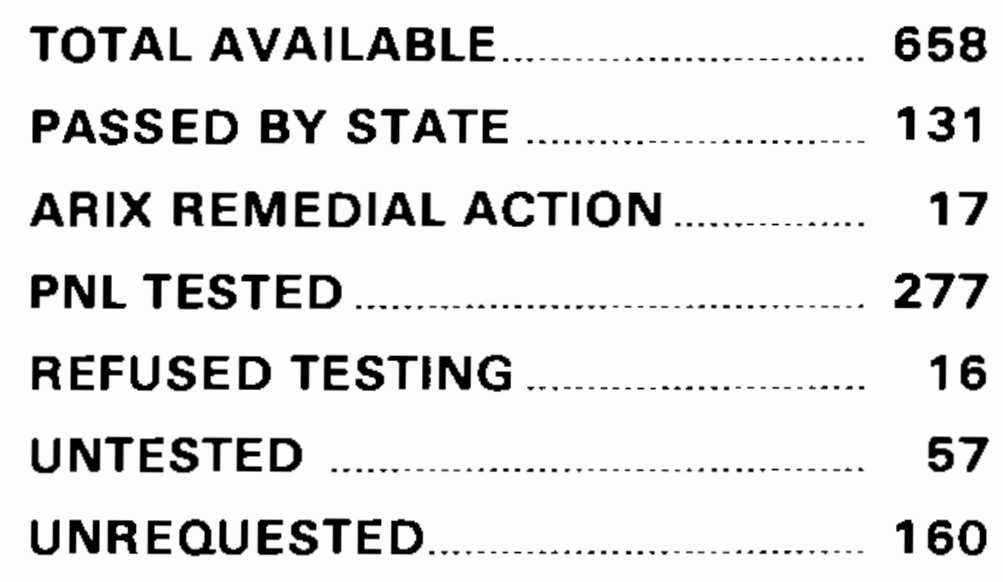


Table 2

\section{STATISTICAL SUMMARY}

VACANT LAND AND MOBILE HOME SITES

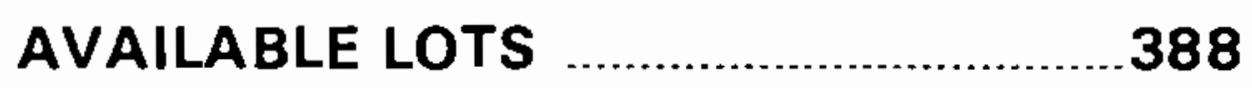

AVAILABLE TRACT BLOCKS ..............66

LOTS TESTED ....................................... 37

LOTS REFUSED TESTING …................ 4

LOTS UNTESTED

LOTS UNREQUESTED ............................267

BLOCKS UNREQUESTED ...................... 66 
There are 388 vacant lots and 66 tract blocks in Edgemont and its vicinity. A mobile home is classified as a residence unit if it rests on a concrete foundation on its own lot. However, if the mobile home is not on a foundation or is in a mobile home park, it is assumed that it will be there only temporarily, and the lot is classified as a vacant lot. A tract block is a large block of land that has not been sub-divided into 1ots. As of January 1, 1981, four lot owners had refused testing, and 267 had not requested a survey. PNL has surveyed 37 lots, but has not yet surveyed 87 lots for which testing has been requested.

\section{Indoor Radon Progeny Working Levels}

The relative numbers of residence units that had working levels within different intervals during the initial five-minute measurement are shown in histogram form in Figure 6, and are plotted on log-probability paper in Figure 7. Thirty-two percent of the working levels were below $0.01 \mathrm{WL}, 45 \%$ were between $0.010 \mathrm{WL}$ and $0.033 \mathrm{WL}$, and $23 \%$ were above $0.033 \mathrm{WL}$. The median working level was $0.016 \mathrm{WL}$. However, many of the measurements were not considered to be valid and are being repeated because (1) wind speeds prior to measurement were greater than $8 \mathrm{mph}$, (2) calculated turnover times were less than 32 minutes, or (3) outdoor working levels were too high. Figure 7 shows the frequency distribution of only the valid working level measurements. When the invalid measurements were excluded, the percent of residences with working levels below 0.01 WL decreased from $32 \%$ to $18 \%$, the percent between $0.01 \mathrm{WL}$ and $0.033 \mathrm{WL}$ increased from $45 \%$ to $56 \%$, the percent above $0.033 \mathrm{WL}$ increased from $23 \%$ to $28 \%$, and the median increased from $0.016 \mathrm{WL}$ to $0.020 \mathrm{WL}$. Figure 8 shows that the five-minute radon progeny measurements succeeded in freeing about half the structures from the requirement of long-term working level measurements. 
FIGURE 6. FREOUENCY DISTRIBUTION OF ALL ORIGINAL 5 MINUTE RADON PROGENY MEASUREMENTS

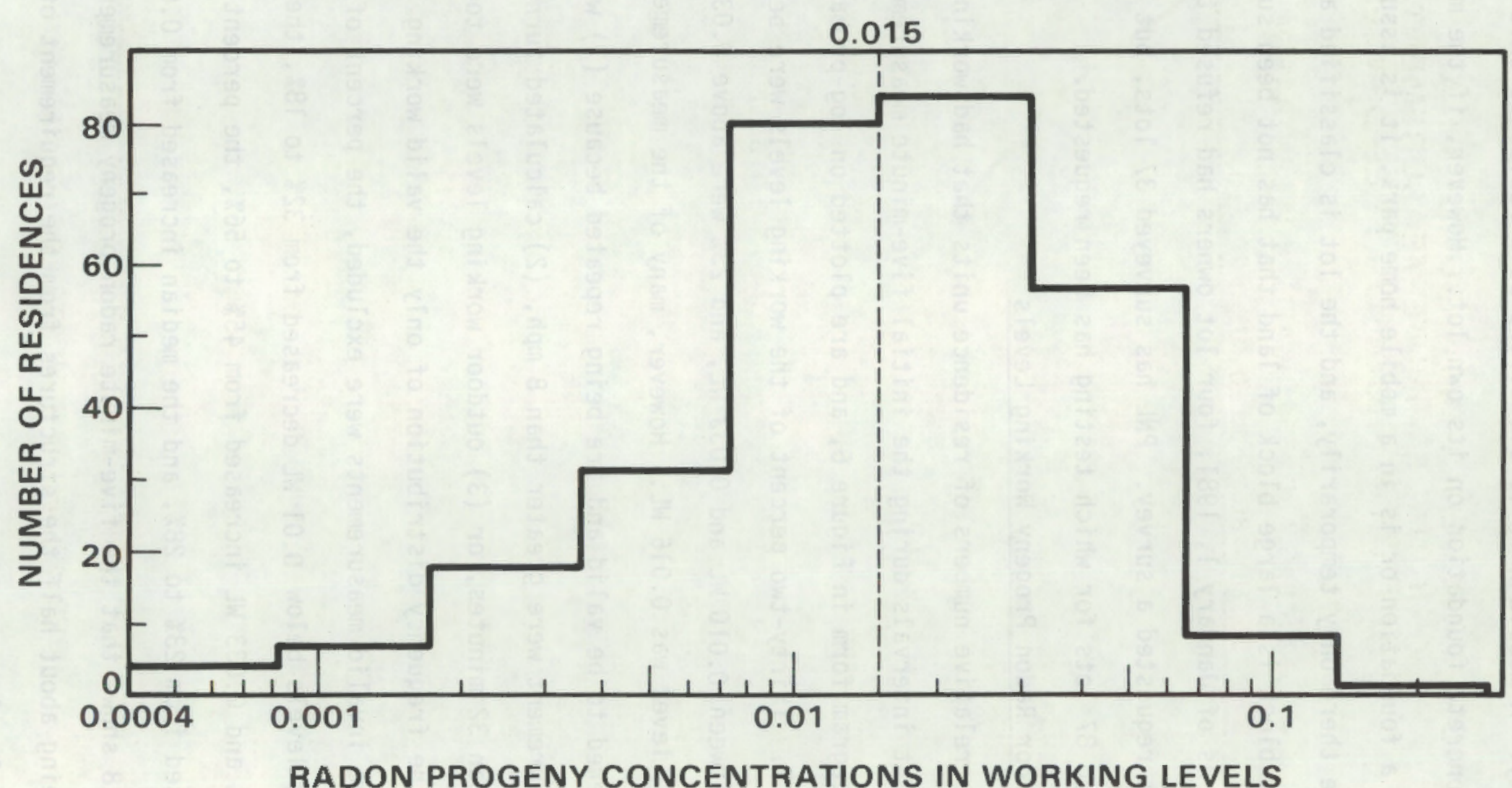


FIGURE 7. FREQUENCY DISTRIBUTION OF ALL ORIGINAL 5 MINUTE MEASUREMENTS OF RADON PROGENY IN RESIDENCES

PERCENT ABOVE INDICATED CONCENTRATION

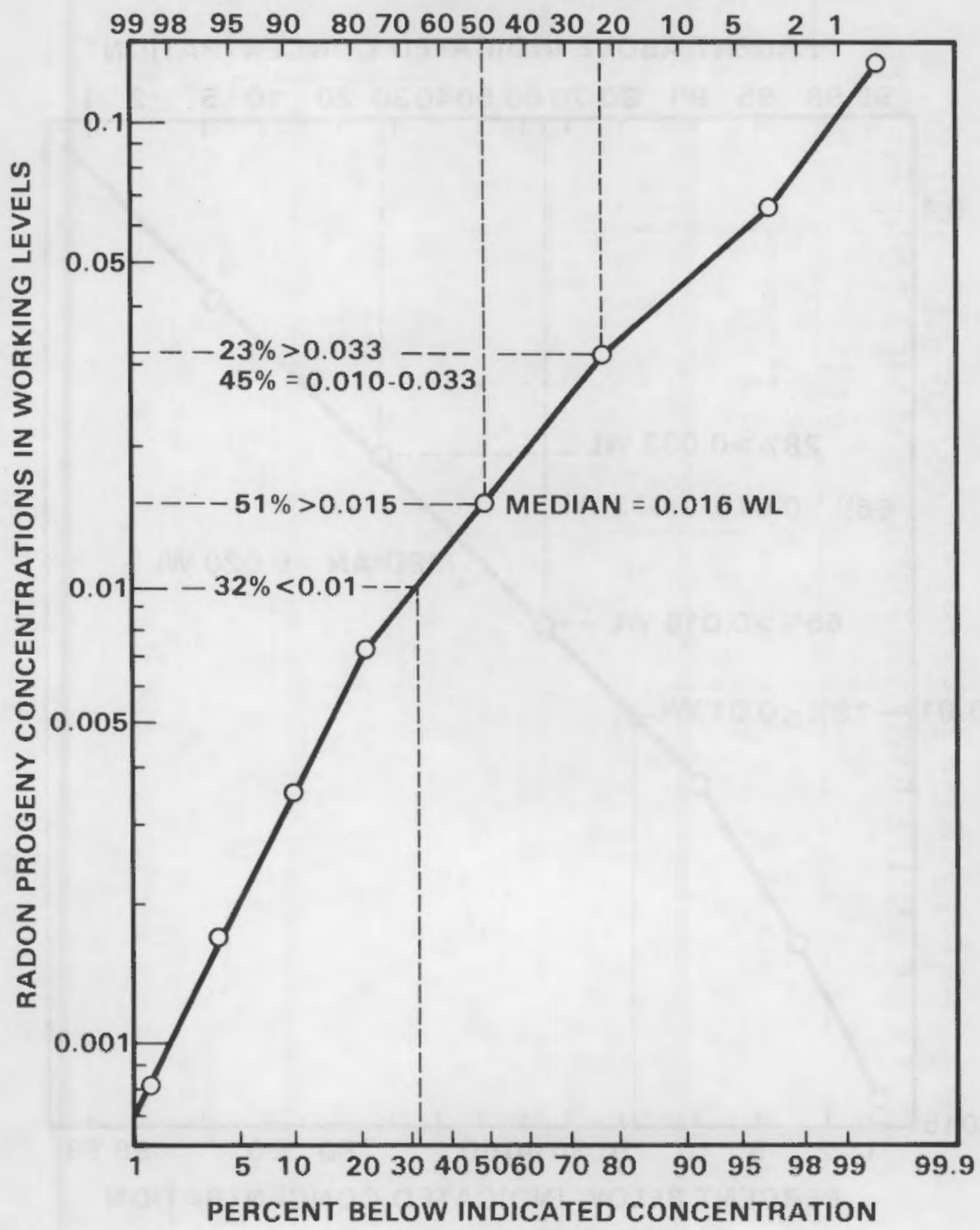


FIGURE 8. FREQUENCY DISTRIBUTION OF ORIGINAL 5 MINUTE RADON PROGENY MEASUREMENTS IN RESIDENCES WHEN WIND SPEEDS WERE BELOW $8 \mathrm{mph}$ AND "TURNOVER TIMES" WERE GREATER THAN 32 MINUTES

PERCENT ABOVE INDICATED CONCENTRATION

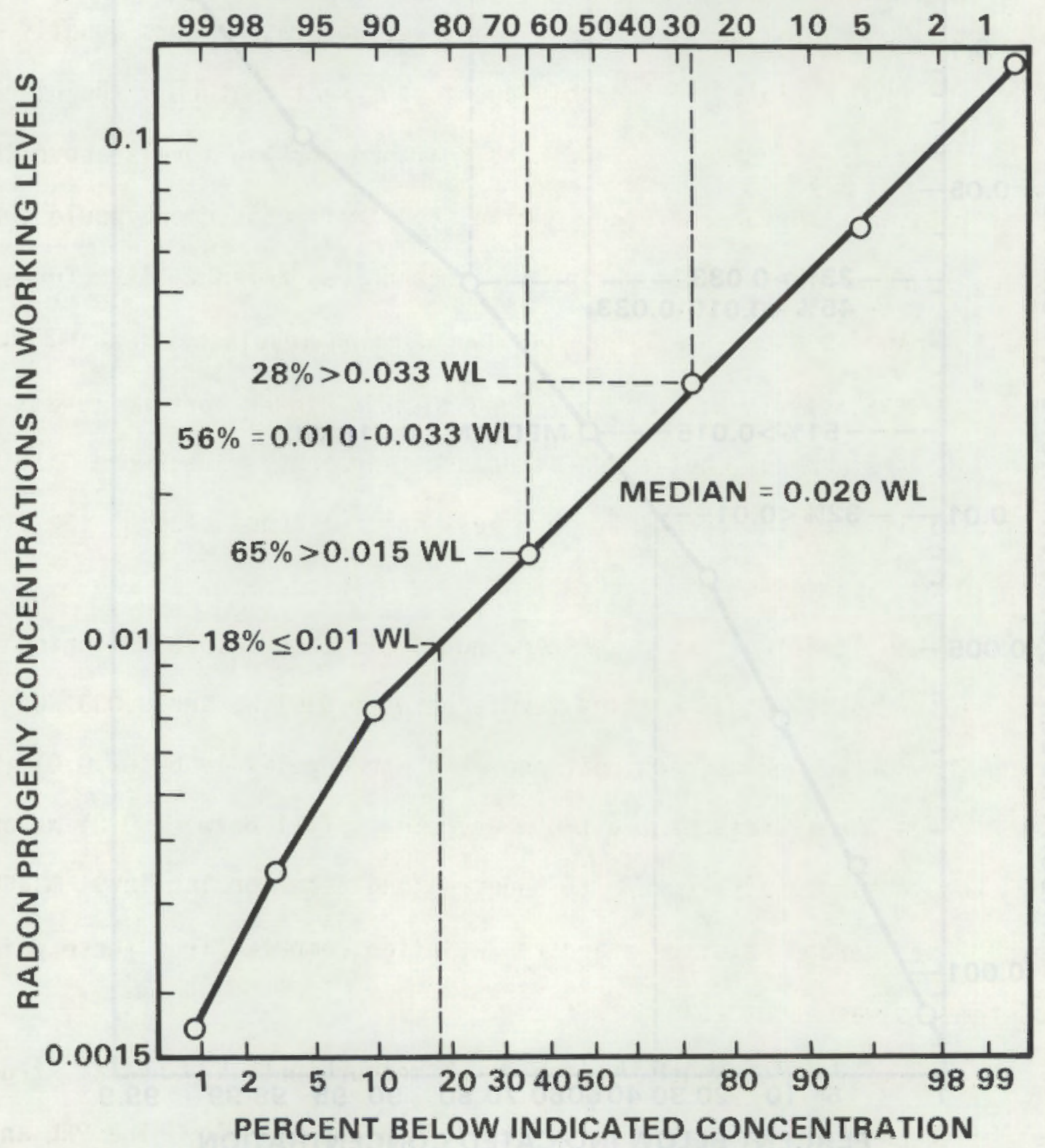


The measured working levels averaged considerably lower when turnover times were shorter than 32 minutes, or when the wind speeds were greater than $8 \mathrm{mph}$ (Figure 9). Under these conditions 55\% of the measured working levels were below $0.01 \mathrm{WL}$, and only $12 \%$ were greater than $0.033 \mathrm{WL}$.

When the working level in a structure was greater than 0.033 WL during the first measurement, the measurement was repeated at a later date to confirm the elevated working level. The first and second measurements are compared in Figure 10. The figure shows that second measurements usually were lower than first. This was probably due to the fact that only the highest measurements were repeated. Structures that had working levels above their normal (closed structure) average during the first measurement would tend to show lower working levels during the second measurement. Structures whose normal average is above $0.033 \mathrm{Wh}$, but had working levels below $0.033 \mathrm{WL}$ during the first measurement, would have tended to show higher working levels during the second measurement, but these structures were not re-measured. It is also possible that the occupants were less careful about closing the structure prior to the second measurement.

Out of 46 structures that had working levels above 0.033 WL during the first measurement, 20 had working levels between 0.01 WL and 0.033 WL during the second measurement, but none had working levels below 0.015 WL. In ten cases the average of the two measurements fell between $0.01 \mathrm{WL}$ and $0.033 \mathrm{WL}$, causing the structure to require long-term working level measurements. The average relative standard deviation computed from these pairs of measurements was about $25 \%$.

PNL has made five minute working level measurements in several structures that had been measured previously by the EPA using RPISU's. The PNL and EPA measurements are reported in Table 3 , and the PNL measurements are also plotted against the EPA measurements in Figure 11. The number of RPISU 
FIGURE 9. FREQUENCY DISTRIBUTION OF RADON PROGENY CONCENTRATIONS IN RESIDENCES WHEN WIND VELOCITIES WERE GREATER THAN $8 \mathrm{mph}$

PERCENT ABOVE INDICATED LEVEL

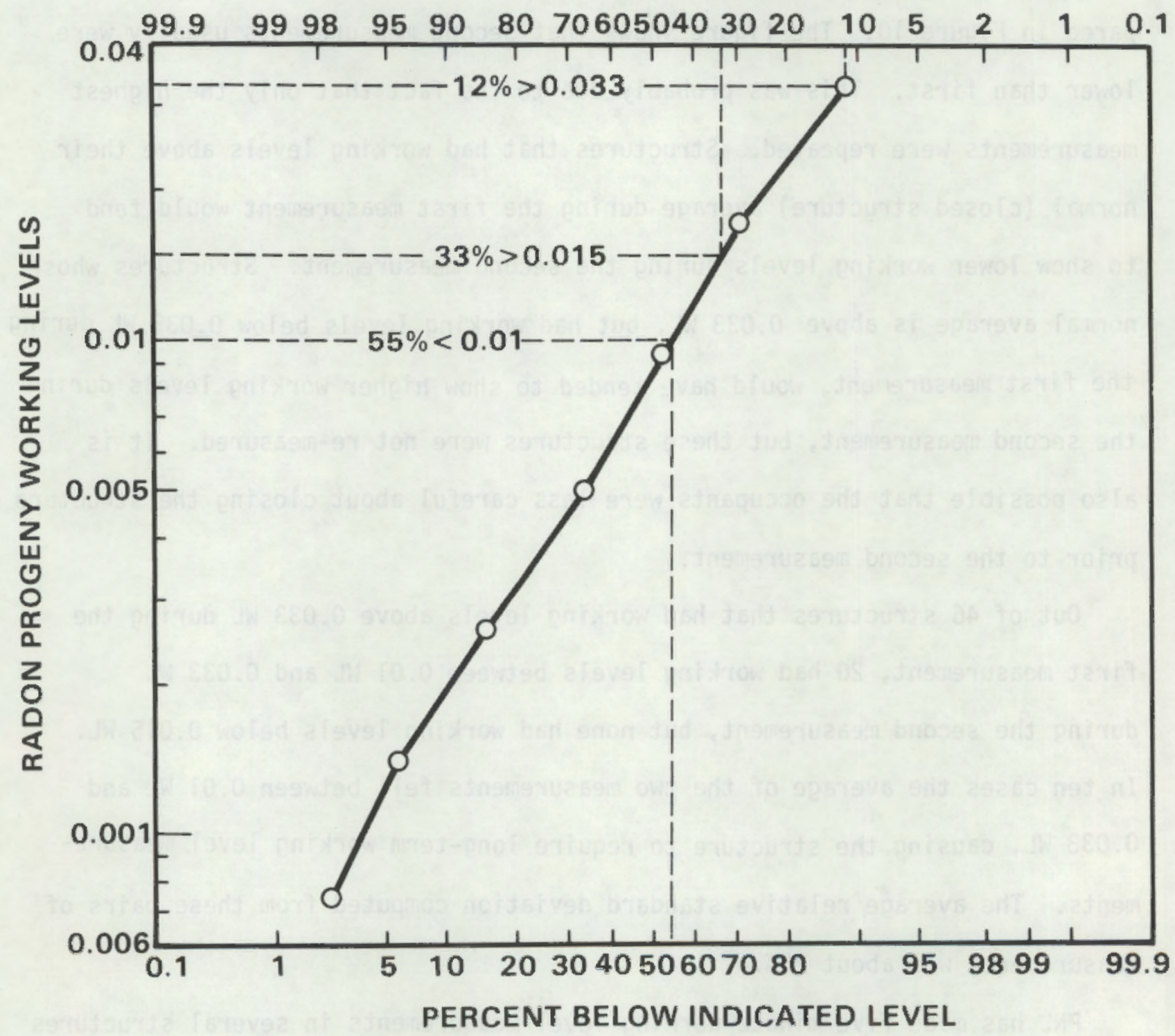


FIGURE 10. COMPARISON OF FIRST AND SECOND RADON PROGENY MEASUREMENTS IN STRUCTURES

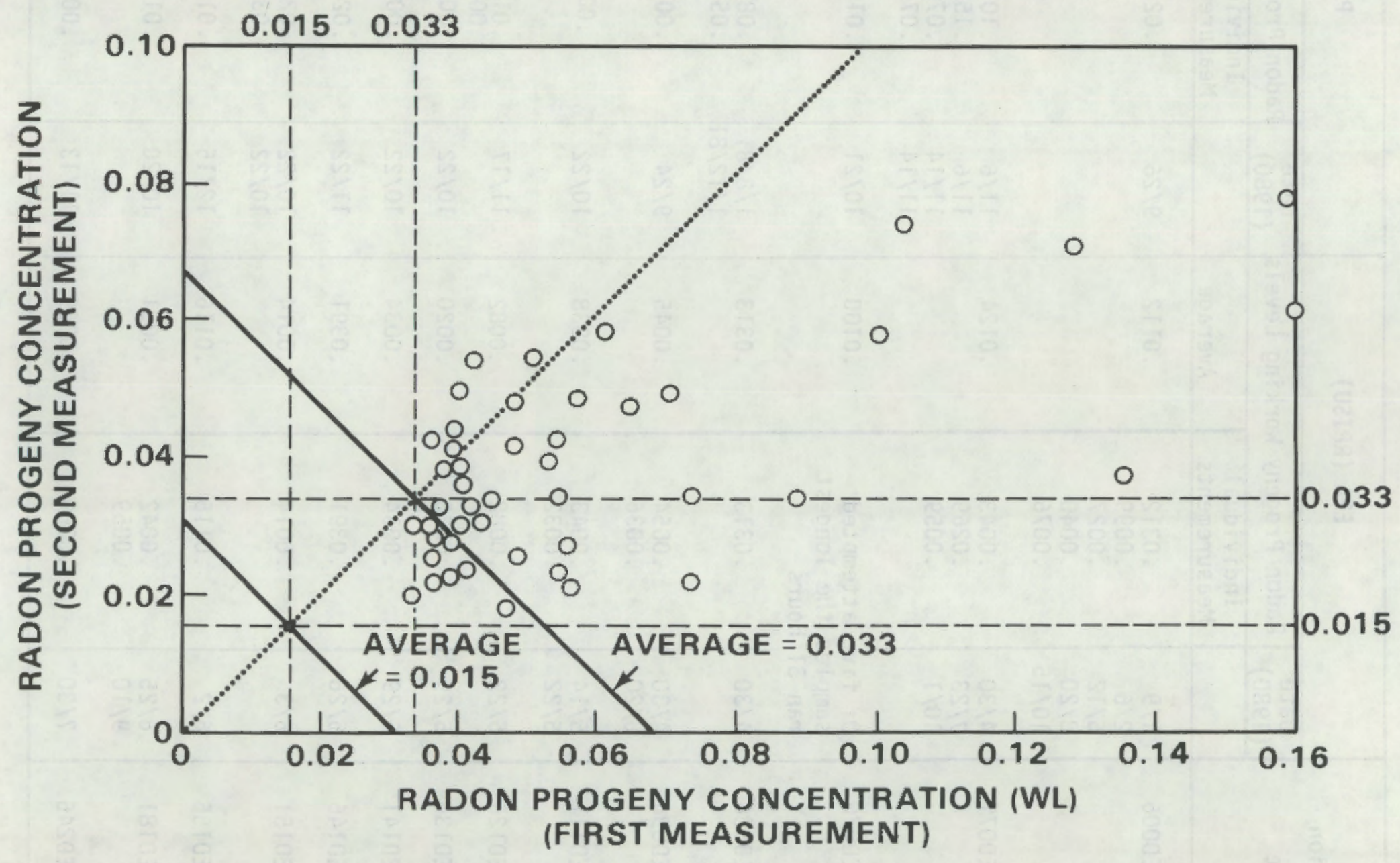


Table 3

COMPARISON OF EPA ANU PNL MEASUREMENTS OF

INDOOR RADON PROGENY CONCENTRATIONS (IN WORKING LEVELS)

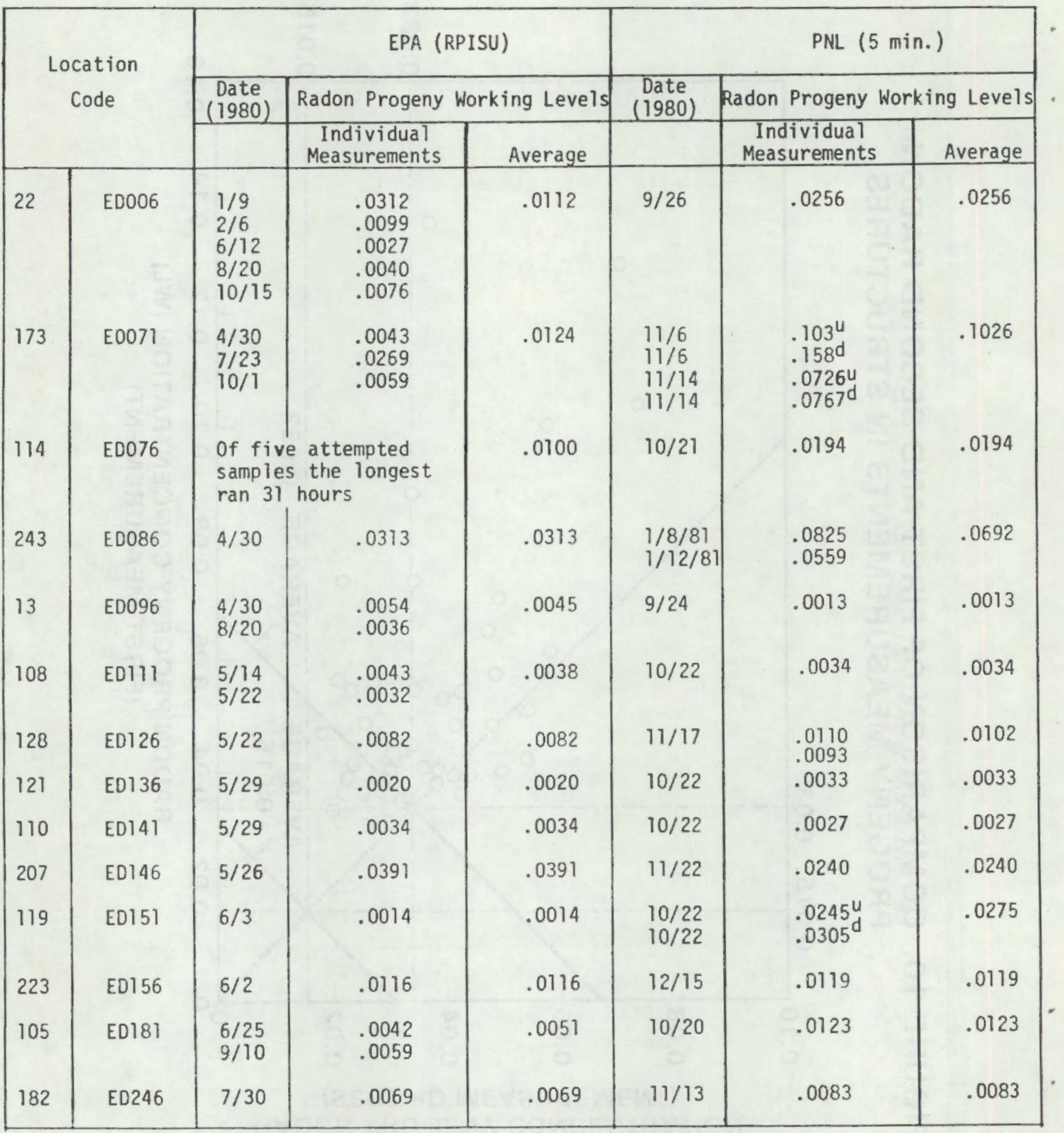

$u=$ Upstairs

$d=$ Downstairs 
FIGURE 11. COMPARISON OF EPA RPISU WORKING LEVEL MEASUREMENTS AND PNL 5 MINUTE MEASUREMENTS

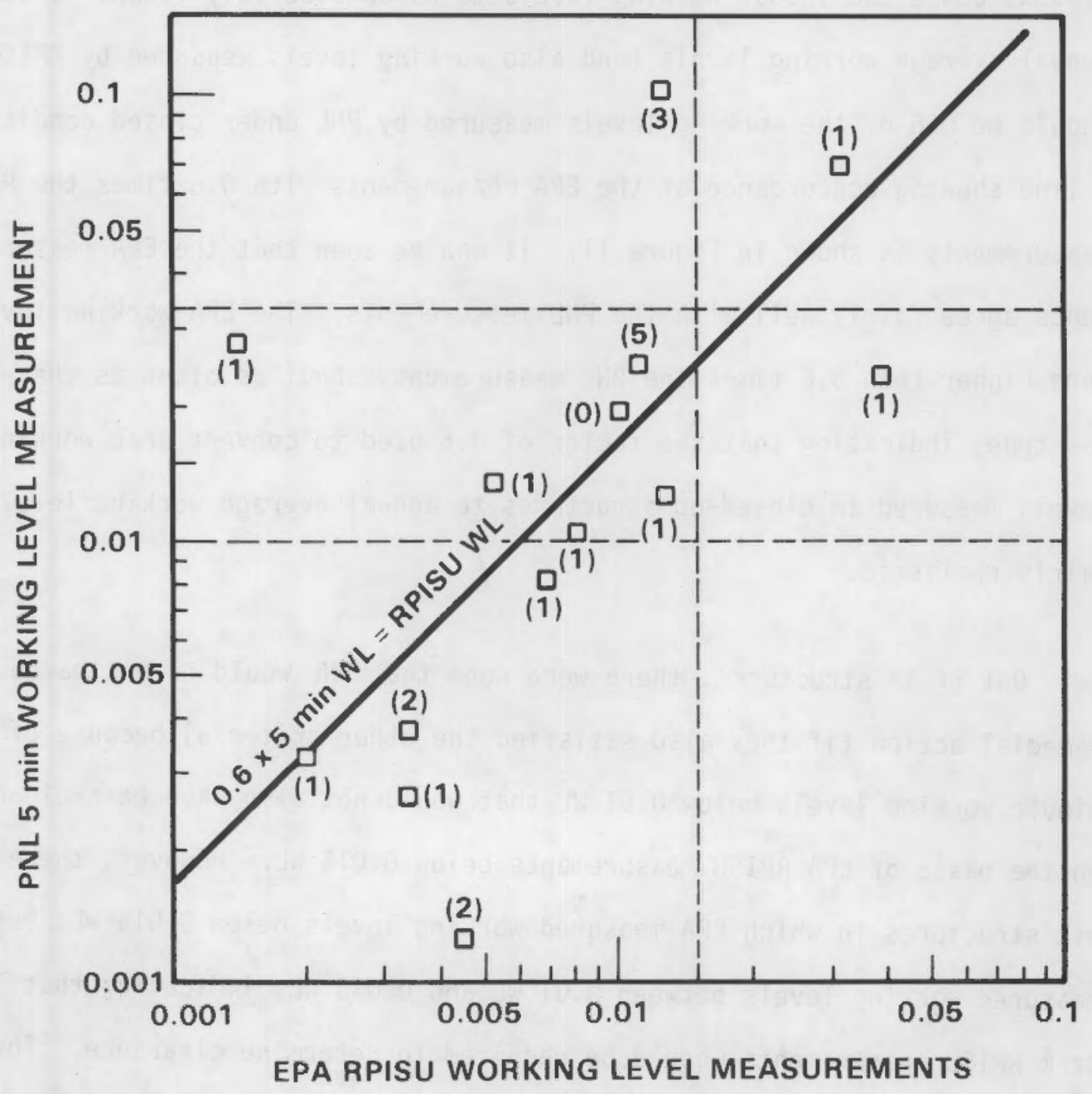


measurements upon which the EPA number is based is shown in parentheses next to the experimental points in the figure. All of the EPA working levels are based upon less than six 100 hour samples, so they do not satisfy the PNL protocol for the determination of annual averages.

It has been estimated that structures at Edgemont are in a closed condition about 0.6 of the time, and that the rest of the time open doors and windows cause the indoor working levels to be considerably lower. Therefore, annual average working levels (and also working levels measured by RPISU's) should be 0.6 of the working levels measured by PNL under closed conditions. A line showing concordance of the EPA measurements with 0.6 times the PNL measurements is shown in Figure 11. It can be seen that the EPA measurements agree fairly well with the PNL measurements. The EPA working levels were higher than 0.6 times the PNL measurements about as often as the reverse was true, indicating that the factor of 0.6 used to convert grab working levels measured in closed-up structures to annual average working levels is fairly realistic.

Out of 14 structures, there were none that PNL would have cleared from remedial action (if they also satisfied the other criteria) because of five minute working levels below 0.01 WL that would not also have been cleared on the basis of EPA RPISU measurements below $0.015 \mathrm{WL}$. However, there were six structures in which EPA measured working levels below $0.015 \mathrm{WL}$, but PNL measured working levels between $0.01 \mathrm{WL}$ and $0.033 \mathrm{WL}$, indicating that longterm RPISU measurements whould be required to determine clearance. There was also one structure in which RPISU measurements showed a working level somewhat lower than $0.015 \mathrm{WL}$, but that PNL measurements above $0.033 \mathrm{WL}$ indicated that engineering assessment would be required. There was only one structure which would have required engineering assessment on the basis of both the PNL and the EPA measurements. In summary, it appears that the PNL 
clearance criterion based on five minute working level measurements does not result in the clearance of structures that should not be cleared, based on long-term RPISU measurements. However, more data is required to determine whether structures are being scheduled for engineering assessment when they should not be. Because of the limited number of RPISU measurements, conclusions drawn from these comparisons should be viewed with caution.

\section{Indoor Gamma Surveys}

The frequency distribution of maximum gamma exposure rates (including contact readings) in residences is shown in Figure 12. Almost all of the residences had maximum readings below $14.5 \mu \mathrm{R} / \mathrm{hr}$ (including background). The median of the maximum exposure rates was $10.4 \mu \mathrm{R} / \mathrm{hr}$. Only four of the residences required engineering assessment because of gamma readings greater than $20 \mu \mathrm{R} / \mathrm{hr}$ above the $14.5 \mu \mathrm{R} / \mathrm{hr}$ background (other residences will require engineering assessment because of high working levels, of course).

\section{Outdoor Garma Surveys}

The frequency distribution of maximum outdoor exposure rates is shown in Figure 13. Only eight percent of the properties surveyed had maximum gamma rates greater than $20 \mu \mathrm{R} / \mathrm{hr}$ above the $14.5 \mu \mathrm{R} / \mathrm{hr}$ background. The curve shows a break below $20 \mu \mathrm{R} / \mathrm{hr}$ (including background), indicating that there are at least two populations of properties, presumably one with residual radioactivity and one without. The points above $20 \mu \mathrm{R} / \mathrm{hr}$ form a straight line, indicating that the properties with residual radioactivity form a log-normal distribution. The frequency distribution of only the properties that had maximum outdoor gamma rates below $17 \mu \mathrm{R} / \mathrm{hr}$ (including background) is shown in Figure 14. These "background" properties formed a fairly lognormal distribution, although there was some scatter at low gamma exposure rates, due to the small number of measurements at these low rates. The median of the maximum gamma exposure rates of these "background" properties was $12.8 \mu \mathrm{R} / \mathrm{hr}$, very close to the average background of $13.2 \mu \mathrm{R} / \mathrm{hr}$ measured by the EPA. 
FIGURE 12. DISTRIBUTION OF MAXIMUM INDOOR GROSS GAMMA EXPOSURE RATE MEASUREMENTS

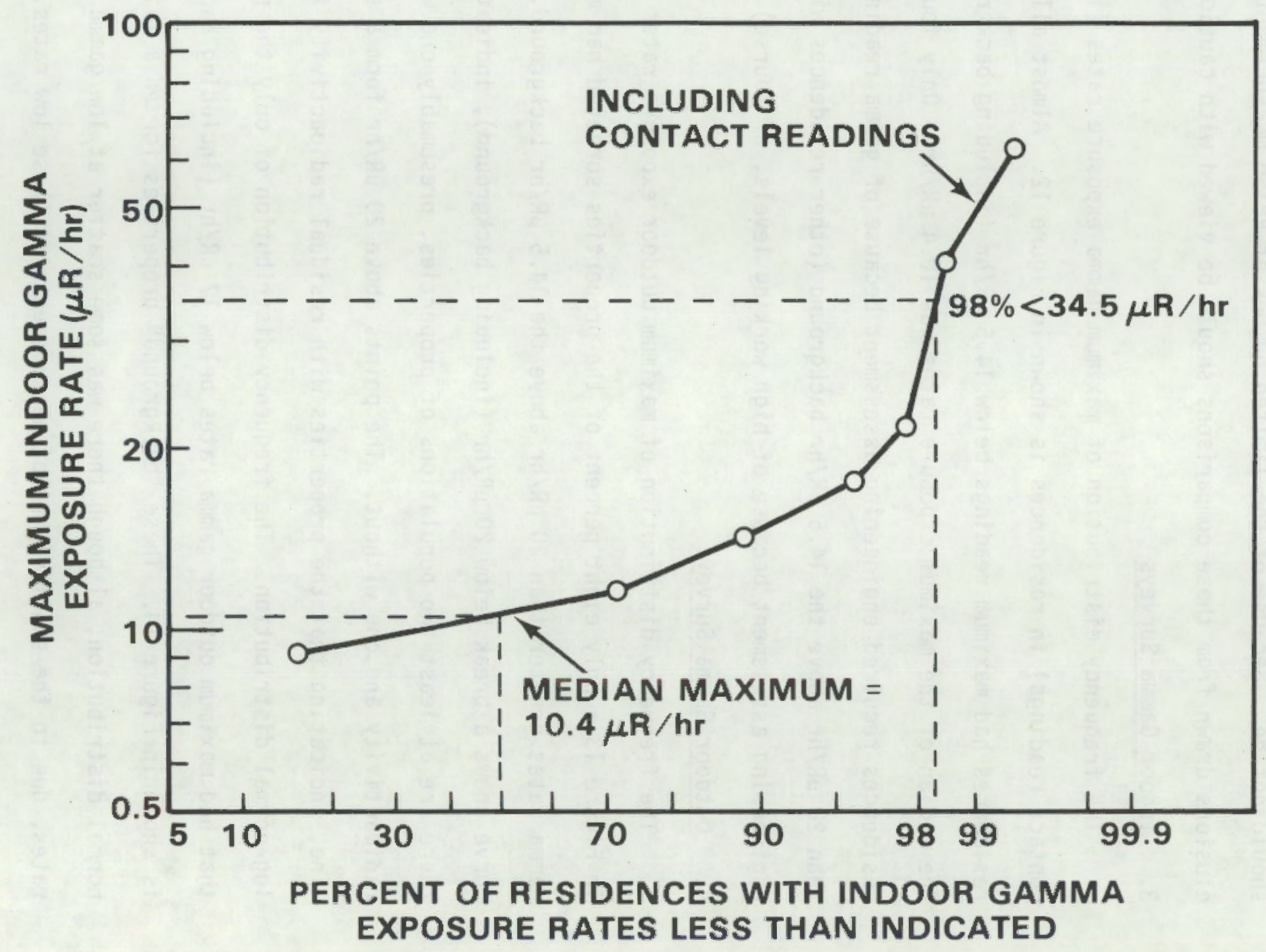


FIGURE 13. FREQUENCY DISTRIBUTION OF MAXIMUM GAMMA RATES AT OUTDOOR SITES

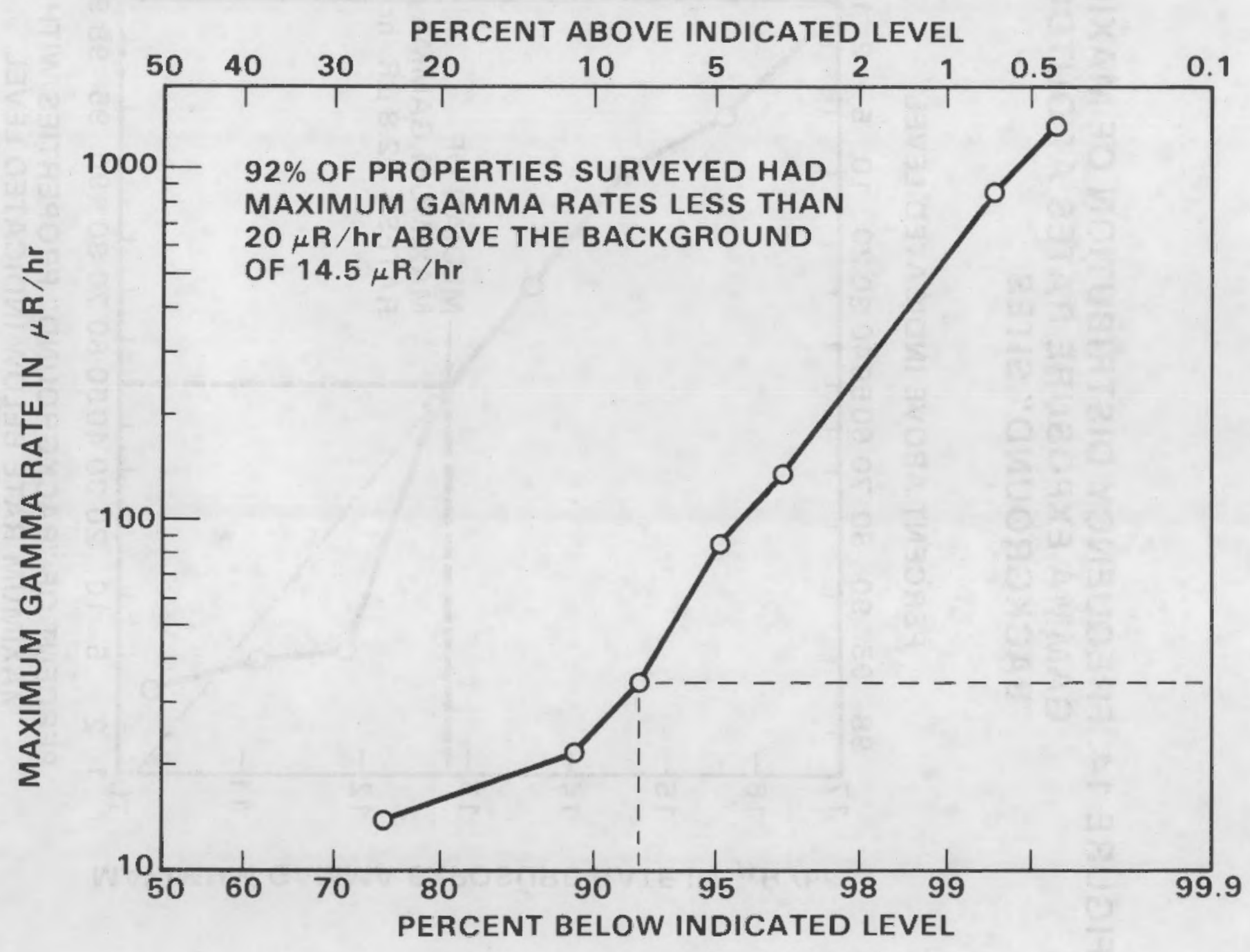


FIGURE 14. FREQUENCY DISTRIBUTION OF MAXIMUM GAMMA EXPOSURE RATES AT OUTDOOR "BACKGROUND" SITES

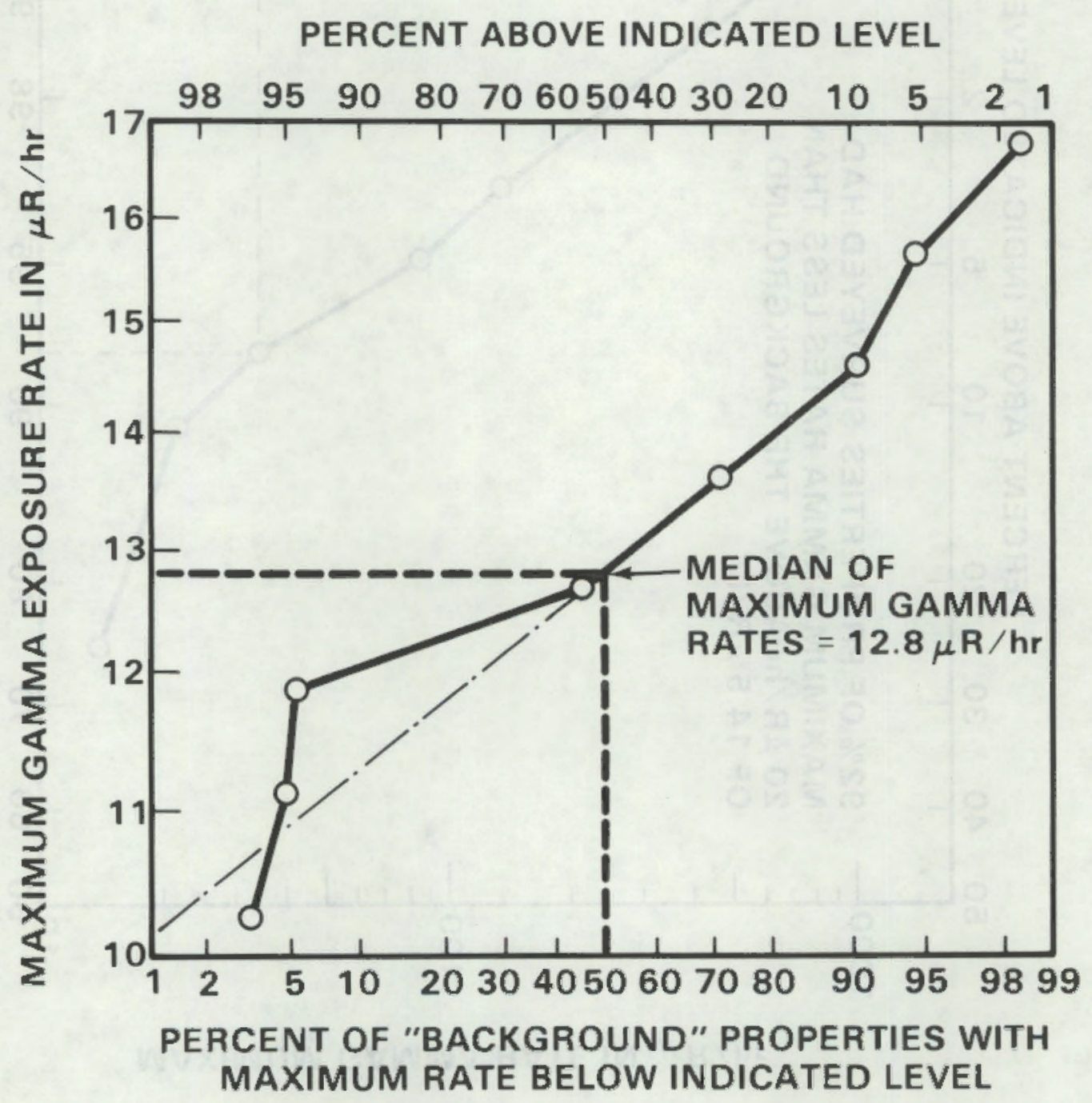




\section{5. ${ }^{226} \mathrm{Ra}$ Concentrations in Soil}

In Figure 15 , the ${ }^{226} \mathrm{Ra}$ concentrations in surface soil samples are plotted against the contact gamma exposure rates taken at the same locations to indicate how well the contact gamma exposure rates predict the ${ }^{226}$ Ra concentrations. Each point on the line in the figure represents the average of all of the ${ }^{226} \mathrm{Ra}$ concentrations at that gamma exposure rate. Only six of the 314 soil samples collected at locations with gamma exposure rates of $8-13 \mu R / h r$ contained greater than $5 \mathrm{pCi} / \mathrm{g}$ of ${ }^{226} \mathrm{Ra}$, and none of these samples contained greater than $6 \mathrm{pCi} / \mathrm{g}$. Therefore, surface gamma exposure rates of $13 \mu \mathrm{R} / \mathrm{hr}$ or less provided a very reliable indication that surface soi containing greater than $5 \mathrm{pCi} / \mathrm{g}$ was not present.

Radium-226 concentrations in soil greater than $5 \mathrm{pCi} / \mathrm{g}$ became more probable at contact gamma exposure rates of 14 or $15 \mu \mathrm{R} / \mathrm{hr}$, and the ${ }^{226} \mathrm{Ra}$ concentrations increased rapidly with gamma exposure rates at higher exposure rates. However, the increase in the average ${ }^{226} \mathrm{Ra}$ concentrations was rather irregular, only partly because there were few measurements at the higher rates. Part of the irregularity was due to the fact that the gamma exposure rates depended not only upon the ${ }^{226}$ Ra concentration, but also upon the area of the elevated ${ }^{226} \mathrm{Ra}$ concentrations. In a few cases the sizes of deposits with the elevated ${ }^{226} \mathrm{Ra}$ concentrations were estimated from contact gamma exposure rate measurements. The ${ }^{226} \mathrm{Ra}$ concentrations and the maximum contact gamma exposure rates are plotted for these recorded cases in Figure 15, and the surface areas of the anomalies indicated. Small areas of elevated ${ }^{226} \mathrm{Ra}$ concentrations produced much lower gamma exposure rates than did large areas.

\section{6. $\quad 238 \mathrm{U}$ Progeny Concentrations in Soil}

The concentrations of ${ }^{238} \mathrm{U}$ (measured as ${ }^{234} \mathrm{Th}$ ), ${ }^{230} \mathrm{Th},{ }^{226} \mathrm{Ra}$, and ${ }^{210} \mathrm{~Pb}$ in samples of tailings material, local alluvial soil, and local bentonite clay are reported in Table 4 and the ratios of ${ }^{230} \mathrm{Th},{ }^{226} \mathrm{Ra}$ and 
FIGURE 15. COMPARISON OF OUTDOOR GAMMA EXPOSURE RATES AND ${ }^{226}$ Ra CONCENTRATIONS IN SURFACE SOIL SAMPLES

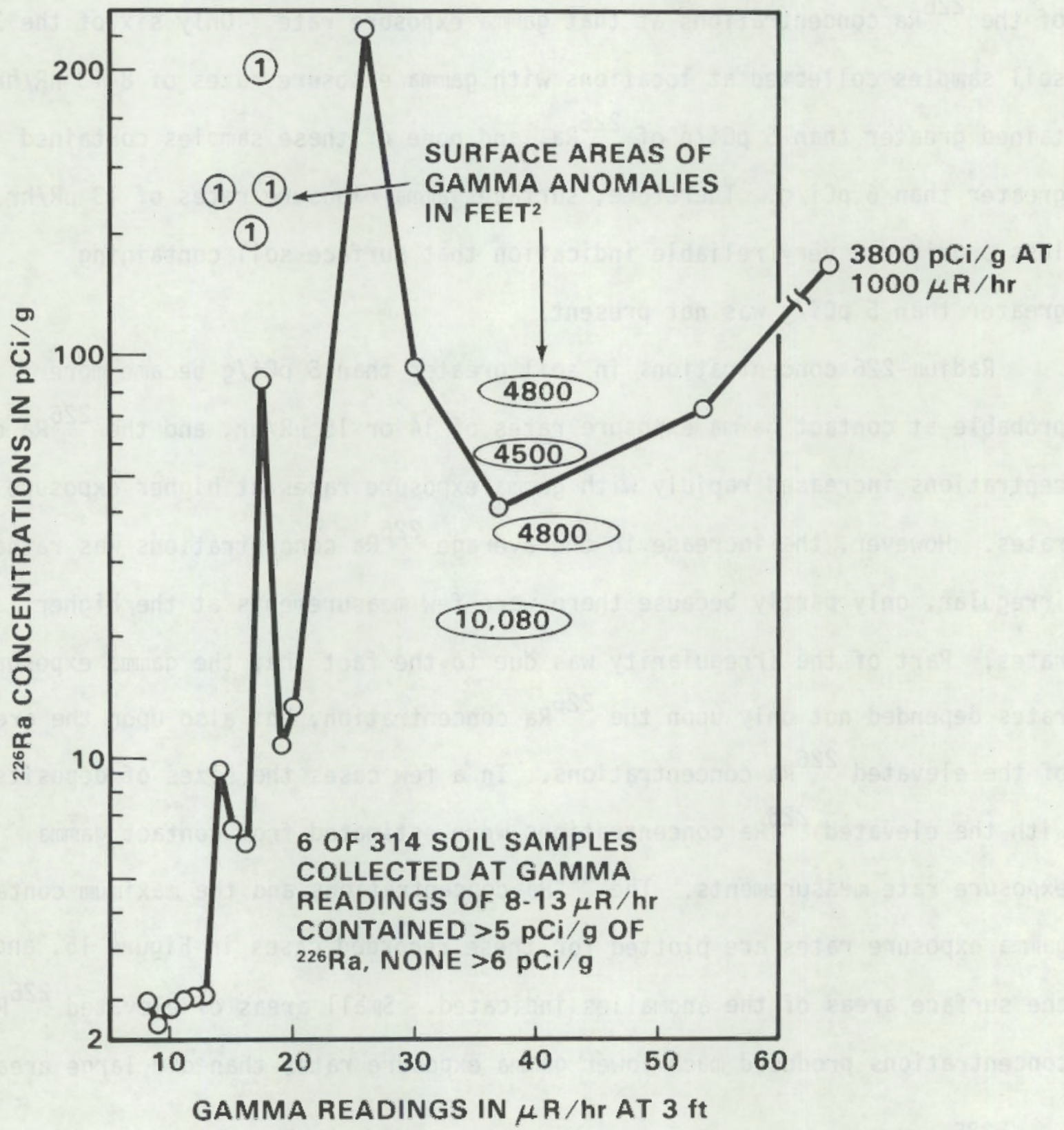




\section{CONCENTRATIONS OF LONG-LIVED ${ }^{238}$ U PROGENY} IN REFERENCE SOIL SAMPLES

\begin{tabular}{|c|c|c|c|c|}
\hline DESCRIPTION & ${ }^{238} \mathrm{U}$ & ${ }^{230} \mathrm{Th}$ & ${ }^{226} \mathrm{Ra}$ & $210 \mathrm{~Pb}$ \\
\hline & & $(\mathrm{pCi} / \mathrm{g})$ & & \\
\hline TAILINGS (PILE A) & 3.2 & 61 & 250 & 240 \\
\hline TAILINGS (PILE A) & 4.4 & 58 & 150 & 150 \\
\hline TAILINGS (EAST PILE) & 4.7 & 15 & 110 & 120 \\
\hline TAILINGS (PILE B) & 2.0 & 42 & 150 & 160 \\
\hline ORE & 970 & 1300 & 960 & 680 \\
\hline LOCAL ALLUVIAL SOIL & 1.4 & 4.1 & 2.5 & 1.3 \\
\hline LOCAL BENTONITE CLAY & 5.3 & 9.8 & 6.6 & 4.9 \\
\hline
\end{tabular}


$210 \mathrm{~Pb}$ to ${ }^{238} \mathrm{U}$ for these materials and for uranium ore are reported in Table 5. It can be seen that the ${ }^{238} \mathrm{U}$ is considerably depleted in the tailings material. However, the ${ }^{238} \mathrm{U}$ concentrations varied from nearly equal to only 2 to 3 times lower than the concentrations of the ${ }^{238} \mathrm{U}$ daughters in uranium ore, bentonite clay, and local alluvial soil. It is apparent that for this tailings material, the ${ }^{226} \mathrm{Ra} /{ }^{238} \mathrm{U}$ ratio is a more sensitive indicator of the presence of mill tailings than is the ${ }^{230} \mathrm{Th} /{ }^{238} \mathrm{U}$ ratio. Lead-210 is also a good indicator, but must be used with caution because of the fallout of airborne ${ }^{210} \mathrm{~Pb}$ from radon.

The ${ }^{238} \mathrm{U},{ }^{230} \mathrm{Th},{ }^{226} \mathrm{Ra}$, and ${ }^{210} \mathrm{~Pb}$ concentrations in a few of the soil samples collected during the Edgemont survey are shown in Table 6 and the ratios of ${ }^{238} U$ to its daughters in these samples are reported in Table 7. Some of the samples containing ${ }^{226} \mathrm{Ra}$ concentrations greater than $5 \mathrm{pCi} / \mathrm{g}$ were significantly depleted in ${ }^{238} \mathrm{U}$, indicating that the ${ }^{226} \mathrm{Ra}$ was due to mill tailings activity, but others had nearly equal concentrations of ${ }^{238_{U}}$ and its daughters, indicating that the ${ }^{226} \mathrm{Ra}$ was due to uranium ore or a natural source.

7. Total Number of Properties Requiring Engineering Assessment

The number of properties surveyed to date that have failed each of the four clearance criteria, and the total number of properties that will require engineering assessment are shown in Table 8 . The sum of the numbers of properties that failed each of the clearance criteria is greater than the total number of properties that will require engineering assessment because many of the properties failed more than one of the clearance criteria.

\section{Outdoor Radon Concentrations}

Radon concentrations have been measured continuously outside the PNL office at Edgemont using an Eberline Radon Gas Monitor, Model RGM-1, since 
Table 5

\title{
DISEQUILIBRIUM OF LONG-LIVED ${ }^{238}$ U PROGENY
} IN REFERENCE SOIL SAMPLES

\author{
SAMPLE \\ DESCRIPTION \\ TAILINGS (PILE A) \\ TAILINGS (PILE A) \\ TAILINGS (EAST PILE) \\ TAILINGS (PILE B) \\ AVERAGE: \\ URANIUM ORE \\ LOCAL ALLUVIAL SOIL \\ LOCAL BENTONITE CLAY
}

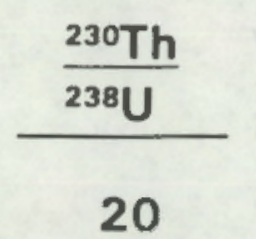

13

5

21

15

1.3

2.9

1.8

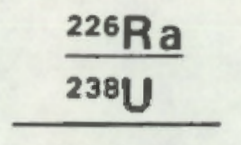

78

34

23

75

52

1.0

1.8

1.2
54

0.70

0.9

0.9 
CONCENTRATION OF ${ }^{238}$ U PROGENY IN SOILS COLLECTED AT GAMMA ANOMALY LOCATIONS

\begin{tabular}{|c|c|c|c|c|}
\hline SAMPLE ID & 238 U & 230Th & ${ }^{226} \mathrm{Ra}$ & ${ }^{210} \mathrm{~Pb}$ \\
\hline SCHOOL A (SURFACE) & 11.8 & 81 & 89 & 112 \\
\hline SCHOOL B (SURFACE) & 2.3 & 5 & 5.6 & 6.0 \\
\hline SCHOOL C (CORE) & 7.1 & 37 & 43 & 51 \\
\hline SCHOOL D (SURFACE) & 3.2 & 68 & 119 & 121 \\
\hline SCHOOLE (SURFACE) & 4.9 & 68 & 164 & 147 \\
\hline SCHOOL F (CORE) & 1.7 & $<3.9$ & 8.1 & 6.1 \\
\hline SCHOOL G (SURFACE) & 2.0 & 5.2 & 2.2 & 2.0 \\
\hline 5C (SURFACE) & 220 & 206 & 222 & 181 \\
\hline 13A (CORE) & 3.4 & 9.7 & 32 & 30 \\
\hline 29B (SURFACE) & 9.3 & 44 & 74 & 75 \\
\hline 57D (CORE) & 70 & 71 & 153 & 91 \\
\hline 57E (SURFACE) & 295 & 328 & 436 & 294 \\
\hline $190 A$ & 7.5 & 10 & 14 & 12.5 \\
\hline
\end{tabular}




\section{DISEQUILIBRIUM OF 238 U PROGENY IN SOILS}

\begin{tabular}{|c|c|c|c|}
\hline SAMPLE I.D. & $230 \mathrm{Th} / 238 \mathrm{U}$ & $226 \mathrm{Ra} / 238 \mathrm{U}$ & $210 \mathrm{~Pb} / 238 \mathrm{U}$ \\
\hline SCHOOL A (SURFACE) & 6.9 & 7.5 & 9.5 \\
\hline SCHOOL B (SURFACE) & 2.3 & 2.4 & 2.6 \\
\hline SCHOOL C (CORE) & 5.2 & 6.1 & 7.2 \\
\hline SCHOOL D (SURFACE) & 21 & 37 & 38 \\
\hline SCHOOL E (SURFACE) & 13 & 30 & 34 \\
\hline SCHOOL F (CORE) & $<2.3$ & 4.8 & 3.6 \\
\hline $\begin{array}{l}\text { SCHOOL G (SURFACE, } \\
\text { NON ANOMALY) }\end{array}$ & 2.5 & 1.1 & 1.0 \\
\hline 5C (SURFACE) & 0.9 & 1.0 & 0.8 \\
\hline 13A (CORE) & 2.9 & 9.5 & 8.8 \\
\hline 29B (SURFACE) & 4.7 & 7.9 & 8.1 \\
\hline 57D (CORE) & 1.0 & 2.2 & 1.3 \\
\hline 57E (SURFACE) & 1.1 & 1.5 & 1.0 \\
\hline $190 A$ & 1.3 & 1.9 & 1.7 \\
\hline
\end{tabular}




\section{MEASUREMENTS REQUIRING ENGINEERING ASSESSMENT AND TOTAL PROPERTIES AFFECTED}

INDOOR GAMMA ANOMALIES OUTDOOR GAMMA ANOMALIES ${ }^{226}$ Ra CONCENTRATION IN SOIL FIVE MINUTE WORKING LEVEL

TOTAL NUMBER OF PROPERTIES
4

20

32

31 (IN DUPLICATE)

62 
September of 1980. This instrument draws air through a filter to remove radon daughters, and then through a scintillation cell. As the radon decays, some of the radon daughters plate out on the interior surface of the cell. The alpha particles produced by the decay of radon and its daughters strike a $\mathrm{ZnS}(\mathrm{Ag})$ phosphor, producing scintillations that are detected by a photomultiplier. The pulses from the photomultiplier are summed by a digital recorder and printed out at regular intervals to give the average radon concentration for that interval (PNL uses one hour intervals). The radon monitor has been calibrated using a radon chamber at the $U$. S. Bureau of Mines in Oenver, Colorado.

The average daily outdoor radon concentrations for the period from September through December 1980 are shown in Figure 16. The radon concentrations showed large day-to-day variations. The concentrations also showed about a three-fold diurnal variation (in December) with maximum concentrations occurring at night and minimum concentrations occurring during the day (Figure 17). The diurnal variations in the wind speed were the inverse of the radon variations, with maximums occurring in the day and minimums during the night. Presumably, the diurnal radon variations were due primarily to the variations in wind speed and atmospheric stability. The stability would be expected to reach a maximum during the night, inhibiting the upward transport of radon from the lower atmosphere.

Ouring the morning hours the outdoor radon concentrations were often high enough to produce radon daughter concentrations that were above the indoor limit of $0.015 \mathrm{WL}$. The outdoor working level measurements made during the morning outside the PNL office and the radon concentrations measured during the same hour are plotted for November and December of 1980 in Figure 18. Twenty-three percent of the radon daughter measurements were above $0.015 \mathrm{WL}$, indicating that the outdoor working levels may have been 
FIGURE 16. DAILY AVERAGE RADON CONCENTRATIONS AT PNL OFFICE

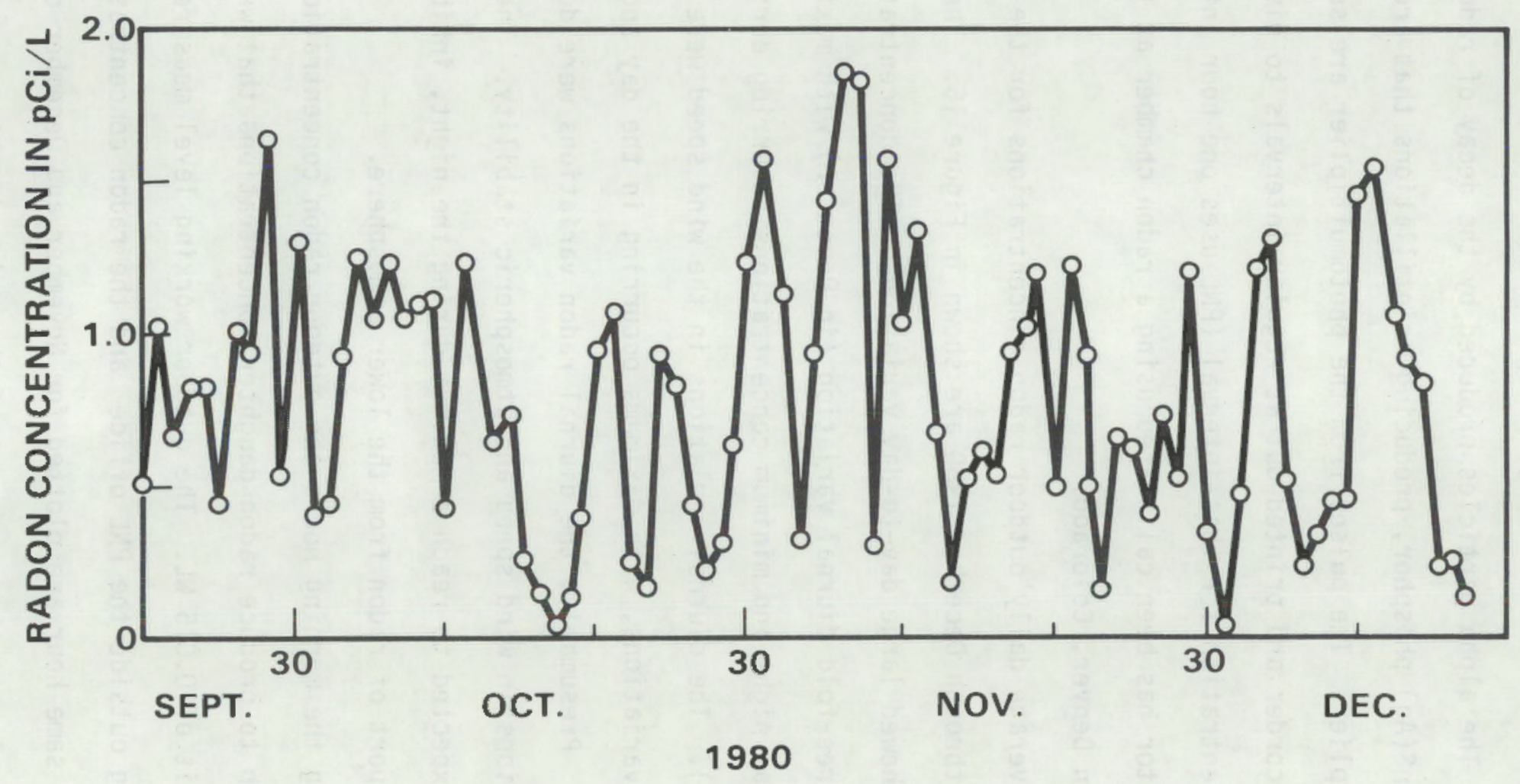


FIGURE 17. AVERAGE DIURNAL RADON VARIATIONS AT THE PNL OFFICE IN EDGEMONT IN DECEMBER OF 1980

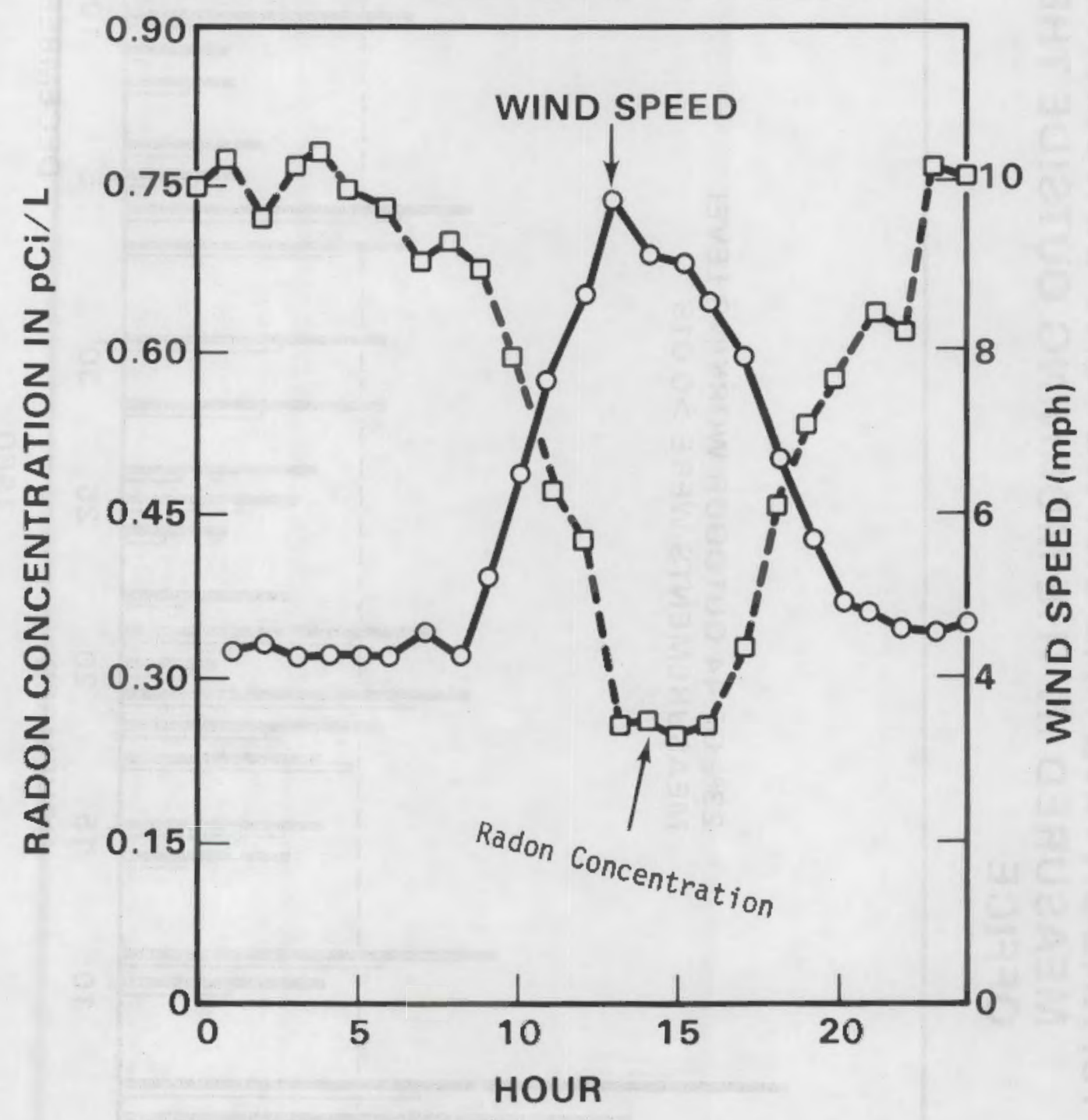


FIGURE 18. RADON AND RADON PROGENY CONCENTRATIONS MEASURED IN THE MORNING OUTSIDE THE PNL OFFICE

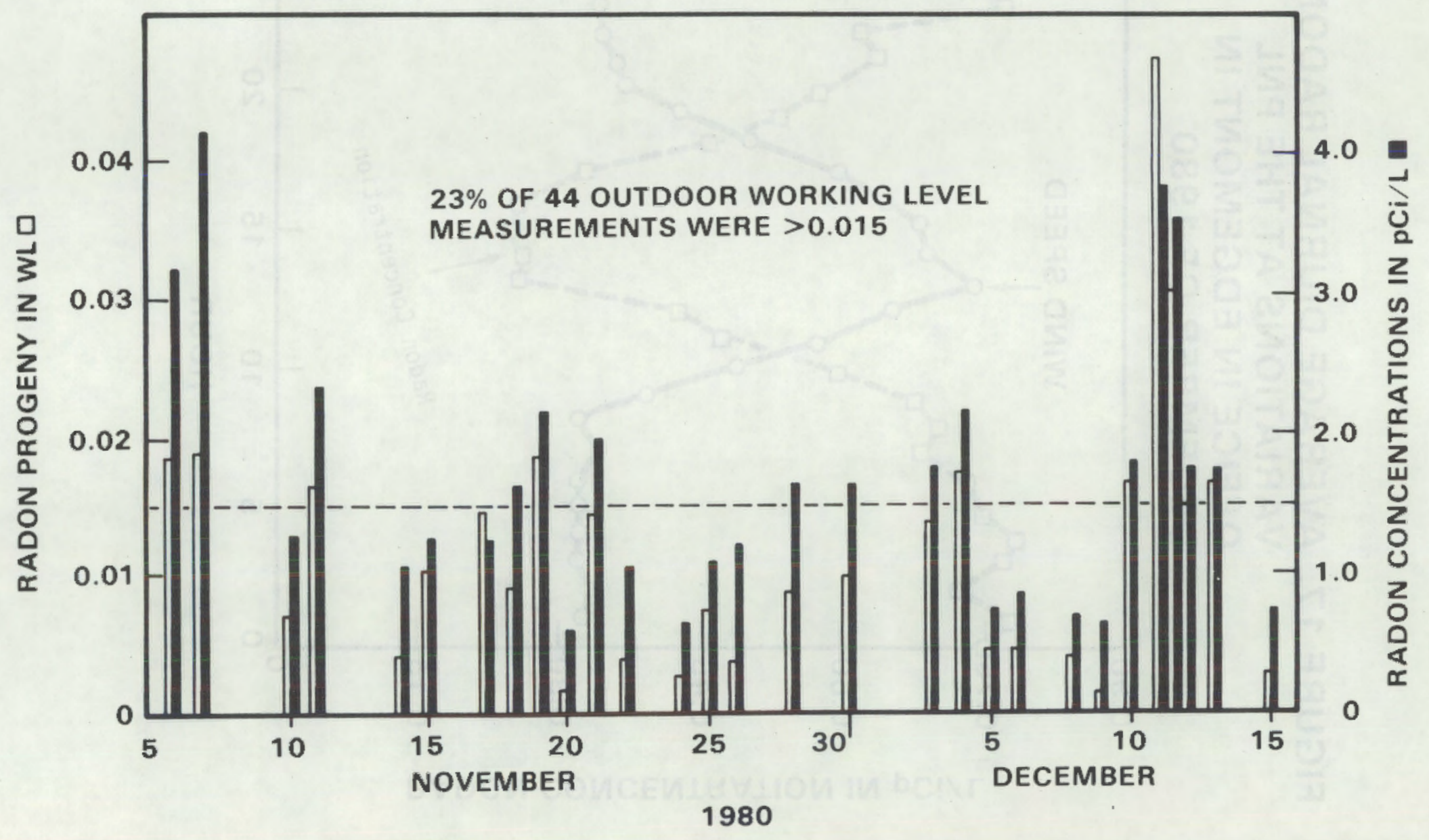


high enough to cause increases in the indoor working levels. However, the outdoor radon and radon daughter measurements that have been made indicate that the outdoor radon daughter concentrations decrease fairly rapidly with time in the morning, so the outdoor radon daughter concentrations may cause problems only during the early morning hours.

Outdoor radon daughter working levels are plotted as a function of wind speed for two wind direction intervals in Figure 19. As expected, the working levels decreased with increasing wind speeds. However, at lower wind speeds the working levels were also lower when the wind was from $010^{\circ}$ to $170^{\circ}$ than when the wind was from $260^{\circ}$ to $320^{\circ}$, which is puzzling because the tailings pile is roughly $110^{\circ}$ from the sampling station. It may be that at these wind speeds the wind direction at the weather station is not representative of the wind direction between the tailings pile and the PNL office because of topographical features. It is also possible that wind directions from $010^{\circ}$ to $170^{\circ}$ are characteristic of weather situations leading to greater vertical mixing than are wind directions from $260^{\circ}$ to $320^{\circ}$. 
FIGURE 19. RADON PROGENY CONCENTRATIONS AS FUNCTIONS OF WIND SPEED AND DIRECTION AT THE PNL OFFICE IN EDGEMONT

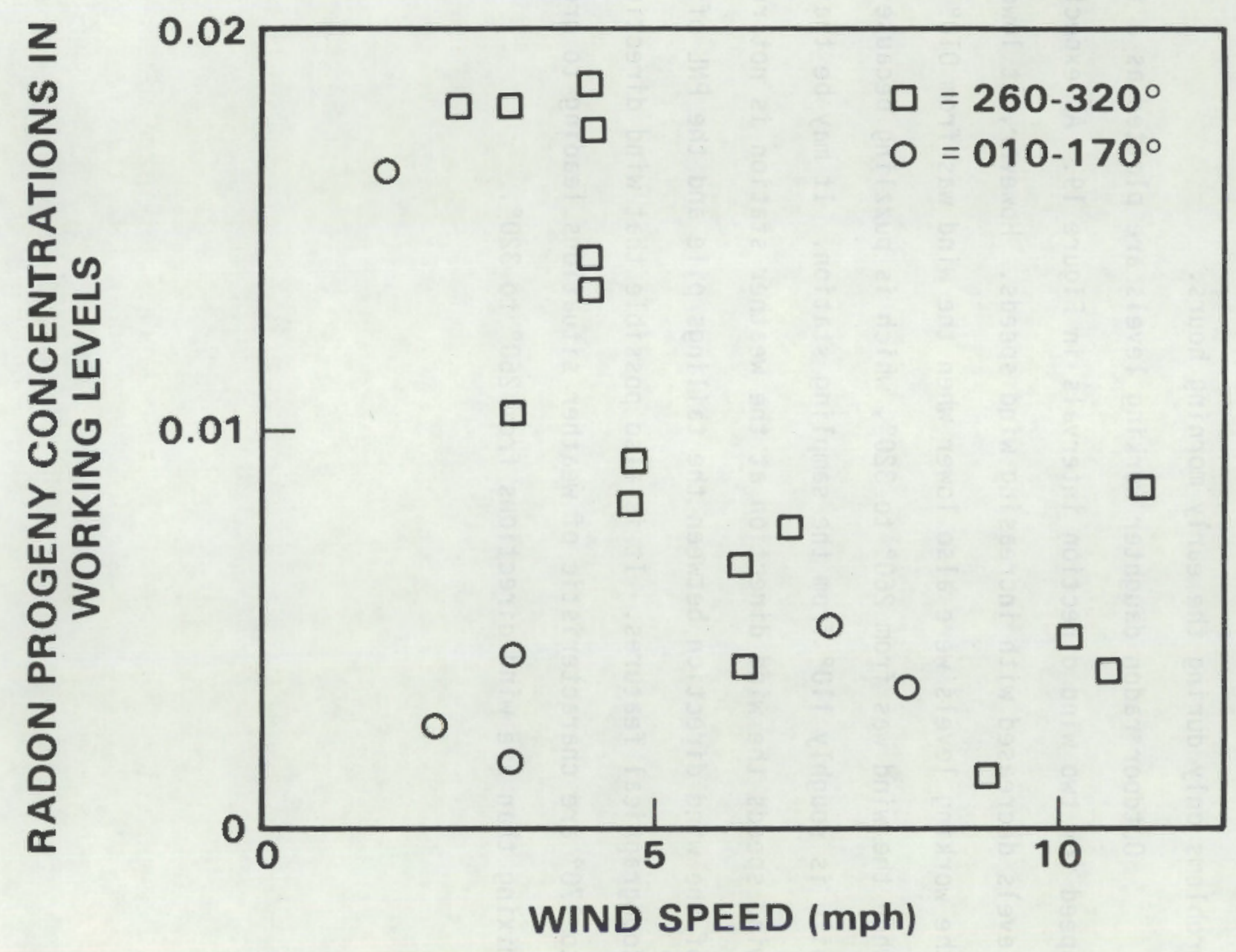


9. Open Discussion of Edgemont Protocols and Radiological Surveys

The afternoon session of the second day was devoted to general and specific viewpoints and recommendations from the attendees, particularly those in government. Comment:

The Grand Junction people feel that radon is a better indicator of long-term exposure than radon daughters. They have made intercomparisons between Track Etch and the RPISU method. K. J. Schaiger's report (in draft form) will show these intercomparisons. Track Etch is shown to be at least as effective as the RPISU. Track Etch is also cheaper. They advocate a year-long measurement.

Comment (Kisieleski, He raised the question of the reproducibjlity ANL): of films, etching, etc.

Comment:

Some concern was expressed about the film consistency from batch to batch, but batches are very large.

Comment (Barrier, Sandia): Terradex's "fluor" film is best. Many calibrations have been performed.

Question (Jackson, PNL): How good are the track counting statistics?

Answer (Bernhardt, EPA): Terradex counts a minimum of four tracks $(\sigma=150 \%)$. They have different levels of reliability for different costs per sample. There is a $\$ 16.50$, a $\$ 33.00$, and a $\$ 66.00$ readout. A cup with filters exposed for one month at one $\mathrm{pCi} / 1$ would yield about six tracks per $5 \mathrm{~mm}^{2}$.

Question (Jackson, PNL): Do electrostatic effects cause problems with plastic cups? Why not use metal cups?

Answer (Bernhardt, EPA): Electrostatic effects appear to be inconsequential for long-term measurements (months) on the plastic cups.

Comment (Haywood, ORNL): He recommended that radon measurements be made. He expressed an intuitive feeling that grab samples are not as good as long-term measurements (Track Etch). He felt that the assumption of $50 \%$ equilibrium is relatively good.

Comment:

The question of tampering with Track Etch was raised. Tampering is easy, but experience has shown less tampering with these passive devices occurs than with active devices.

Question: Is Track Etch permanent?

Answer: Yes. Track Etch is very permanent and stable. 
Comment:

In mining towns ore dust may pose special problems. It is best to assure that no ore dust is transported to the device.

Comment (Groelsema, DOE): As a result of Schiager's report, soon to be issued, DOE will probably propose Track Etch as an acceptable method. A notice to come in Federal Register with call for comments. He noted that Track Etch was a simple integrating sampler. Grab samples will always have inherent variability.

Question (Perkins, PNL): Does even a one-year exposure provide a good estimate of the life-time average for a structure?

Comment:

Seasonai variations are relatively sinusoida], so a six-month measurement may provide a good estimate of the annual average.

Question:

Are we saying that grab samples are not really worthwhile?

Comment (Kisielski, ANL): We must acknowledge that grab sampling has limitations for arriving at an annual average.

Comment:

Track Etch is a more cautious approach. Could be the only measurement needed.

Question (Denham, PNL): Considering the range of values, is the use of a five-minute grab sample really supportable?

Answer (Perkins, PNL): We want to avoid long-term measurements as much as possible to expedite remedial action. The grab samples are used only to screen out those structures whose radon daughter concentrations are so different from the 0.015 WL standard that long-term sampling is not necessary. The average relative standard deviation for the PNL method was about $\pm 25 \%$ (at $0.033 \mathrm{WL}$ ).

Comment (Bernhardt, EPA): Butte data seemed to favor long-term rather than grab samples. The Butte data indicate more uncertainty for grab sampling than is implied from the Edgemont results.

Question (Perkins, PNL): How do we take the best grab sample?

Answer (Langner, CDH): Take it in the winter before the family gets up and turns up the furnace.

Question:

How does the entry of people into an area sampled affect the concentration?

Answer:

Entry does change the levels.

Comment (Langner, $C D H$ ): For best results, move the family out. Plug chimneys, use a radon measuring device. 
Comment (Kisieleski, ANL): This would not be a representative measurement.

Comment (Jackson, PNL): It is not practical to try to move the families out.

Comment (Langner, $\mathrm{CDH}$ ): $\quad$ Future occupants, whatever their life style and ventilation requirements, would be protected.

Comment (Kisieleski, ANL): You might build a representative structure and make measurements in it.

Question (Schwendiman,

Could you make sampling more representative by PNL): having four or more sampling heads running from a common pump, with each head at a different place in the room?

Answer (Jackson, PNL): I believe little would be gained. The variability is more time dependent than spatial.

Comment (Cooperstein, DOE): I am still concerned about HUD's actual needs and requirements. I would expect them to pick conditions to maximize the use factor.

Comment (Perkins, PNL): I'd like to consider what can be done with aerial surveys.

Comment (Cooperstein, DOE): The EG\&G survey covered 9 square miles with Edgemont site at the center, could find few anomalies. The average radiation level was 10-15 $\mu \mathrm{R} / \mathrm{hr}$. A small anomaly occurred at the western side of the school.

Question (Eadie, NRC): Were there other aerial survey-detected anomalies?

Answer (Cooperstein, DOE): Yes, an area to the west of the mill site, using $214 \mathrm{Bi}$.

Question (Groelsema, DOE): What is the terrain to the southeast?

Answer (Momeni, ANL): $\quad$ There are forests and hills, a wind channel.

Question (Perkins, PNL): What is the area and sensitivity of an areal survey?

Answer (Tipton, EGG): The area is about 500 to 600 feet in diameter when the survey is conducted 150 feet above the terrain.

Question (Eadie, NRC): What about sub-surface sources?

Comment (Bernhardt, EPA): It is not necessary to sample below the surface if there is no indication of a radiation anomaly or a historic reason to expect contamination. 
Comment (Cooperstein, DOE): The past history of the site should be considered in determining the likelihood of buried sources.

Comment (Bernhardt, EPA): The indoor standard of $20 \mu \mathrm{R} / \mathrm{hr}$ above background was intended to be a supplementary standard where tailings are present in a structure and the working level standard is met without removal of tailings. It is not intended for use on open lands or outside.

Question:

Is $20 \mu \mathrm{R} / \mathrm{hr}$ consistent with the $5 \mathrm{pCj} / \mathrm{g}$ standard for 226Ra?

Answer:

$20 \mu \mathrm{R} / \mathrm{hr}$ is less sensitive than $5 \mathrm{pCi} / \mathrm{g}$. Five $\mathrm{pCi} / \mathrm{g}$ is more consistent with $5 \mu \mathrm{R} / \mathrm{hr}$ (above background).

Comment:

The $5 \mathrm{pCi} / \mathrm{g}$ standard was proposed because soi] having higher concentrations than this would be expected to produce working levels above $0.015 \mathrm{WL}$ in structures on the site.

Comment (Bernhardt, EPA): Twenty $\mu \mathrm{R} / \mathrm{hr}$ is not intended to be consistent with $5 \mathrm{pCi} / \mathrm{g}$ of $226 \mathrm{Ra}$. It is a supplement to the $0.015 \mathrm{WL}$ standard and is only intended for use when remedial actions other than removing tailings from a structure are used.

Comment (Denham, PNL): I would like to see some depth sampling. I would look for opportunities for trench digging, excavations, etc.

Comment:

Yes. Surprises have been seen when samples were taken at depth.

Question (Cooperstein, DOE):

What is NRC doing about sites where permission has been granted for burial?

Answer (Perkins, PNL):

That is a different problem.

Question (Cooperstein, DOE) :

How does PNL certify "cleanness"?

Answer (Jackson, PNL):

Comment (Cooperstein, DOE):

PNL certifies that the level is within the criteria set by HUD. The PNL investigator signs a letter attesting to this and transmits it to the state.

DOE tries to get survey findings into the land record.

Comment (Jackson, PNL): A computer record of the results would be very helpful.

Comment (Endres, HUD): We do not require an affidavit. HUD maintains records.

Comment (Rarrick, Sandia): Courty records should include appraisals. 
Comment (Jackson, PNL): The certification is made available to the property owner.

Question (Cooperstein, Will NRC do remedial action? DOE):

Answer (Scarano, NRC):

Only if the source is residual radioactivity. Comment (Perkins, PNL):

We plan to do simultaneous indoor and outdoor radon and daughter measurements. We will do some Track Etch measurements and compare some results with RPISU measurement. Some one-year Track Etch measurements will be made. We will try the earphones on the Ludlum instrument.

Comment (Jackson, PNL): We need your comments and recommendations.

Question:

Have measurements been made in Cottonwood?

Answer (Jackson, PNL): $\quad$ No measurements have been made there.

Comment:

I'd recommend gamma measurements using a lead collimator.

Comment (Bernhardt): I'm concerned about adjustments for barometric pressure. We find factor of two changes in working level.

Comment (Jackson): We have not spent much time looking for correlations with barometric pressure. We suspect that the effects of changes in the ventilation rate upon the working levels will overshadow the effects of barometric pressure changes.

Question (Bernhardt, EPA): How do you treat central air systems?

Answer (Jackson, PNL): We let them run the furnace even if we suspect plateout in ducts will lower radon progeny levels.

Question:

Will you measure the contamination on the surface of materials in structures?

Answer (Jackson, PNL): We don't intend to.

Comment:

Comment (Momeni, ANL): We need data on surface contamination release limits.

Comment (Jackson, PNL): Edgemont is a dusty town.

Surface contamination data are more important when tajlings are taken away. Salvage of structures, steelwork may need surface contamination limits.

Comment (Jackson, PNL): He encouraged all present to make intercomparison measurements.

Question:

Do the PNL protocols being used in the Edgemont radiological survey adequately cover EPA guidelines?

Answer (Bernhardt, EPA): He stated that in his opinion the soil sampiing and gamma-ray protocols described at the workshop appear to meet the intent of the EPA standards. 


\section{CONCLUSIONS FROM WORKSHOP}

1. No really important shortcomings of the PNL approach were brought out at the workshop. The purpose of the survey was to identify property requiring remedial action, and to release property that satisfied HUD criteria. The survey was not a research project. HUD does not intend to "split hairs" about meeting EPA clearance critera.

2. The validity of grab working level measurements was questioned by several. However, grab measurements are probably appropriate for the purpose they were intended, which was to screen out structures having working levels much different (either higher or Tower) from the 0.015 WL clearance criteria. However, a statistical study should be made of the grab working levels, the long-term working levels, and the subsequent results of engineering assessments to determine how accurately grab working levels identify structures that either clearly do not, or clearly do require remedial action.

3. There was a strong recommendation for the use of the audible signal and earphones during the gamma radiation surveys.

4. Some believed that more soil samples at greater depth should be taken. However, if no elevated gamma exposure rates or working levels can be detected, then the subsurface residual radioactivity, if any, is not producing a significant radiation dose to the population. When anomalous gamna exposure rates, ${ }^{226}$ Ra concentrations in surface soil, or elevated working levels are observed, core samples and searches for the source of the radiation should be conducted.

5. Several attendees expressed their confidence in Track Etch film techniques and recommended that Schiager's review of the Grand Junction program be studied carefully. The practical worth of these methods is still being questioned. It is clear that further research should be done to determine 
how accurately Track Etch devices determine working levels, and to determine whether some films and techniques of mounting, track developing, calibration, and reading are better than others. This research should be done before replacing RPISU working level measurements with Track Etch measurements, to insure that large numbers of Track Etch measurements of dubious validity are not made.

6. It was mentioned several times that barometric pressure changes affect indoor and outdoor radon and daughter concentrations. Although the Edgemont survey is not a research project, the barometric pressure data should be studied to determine whether it can be useful in accounting for or defining the range of uncertainty of the indoor working level measurements, or in estimating annual averages from either single or multiple five-minute measurements.

7. The question of simultaneous indoor and outdoor radon and daughter measurements was raised several times. As a result of the workshop, radon daughter concentrations are now being measured simultaneously inside and outside of structures being surveyed to identify cases where high outdoor concentrations could be causing increases in indoor concentrations. A large number of comparisons of indoor and outdoor radon and daughter concentrations could help to answer the questions (1) whether radon or radon daughter measurements provide a better measure of the lifetime average working levels in a structure, and (2) whether multiple five-minute measurements or Track Etch can replace RPISUs for determining annual average working levels.

8. The question about the relaionship of outdoor gamma dose rates and the ${ }^{226} \mathrm{Ra}$ concentration of soils does not affect the existing protocol. ${ }^{226}$ Ra measurements are being made for soil at every house regardless of the gamma exposure rates. The use of a gamma exposure rate criterion 
for outdoor surveys covers only those rare cases where there is a small deposit containing ${ }^{226} \mathrm{Ra}$ which the soil core samples miss, so that the radium measurements themselves do not show a need for an engineering assessment.

9. It was felt by many that a similar workshop to discuss the radiation surveys at Butte, Montana, at Edgemont, and at DOE remediar action sites should be held in about a year.

\section{CHANGES IN EDGEMONT PROTOCOLS MADE AS A RESULT OF DISCUSSIONS AT THE WORKSHDP}

As a result of suggestions made by attendees at the Denver workshop, we have made a few changes in the protocols used to conduct radiological surveys at Edgemont. These changes are reported in the protocols, but for the convenience of the reader, they are also listed below.

1. Beginning in February of 1981 , radon daughter concentrations will be measured outside of structures before or during the time that radon daughter measurements are made inside the structures to determine whether the outdoor concentrations can be causing increases in the indoor concentrations. However, if it is found that the outdoor concentrations at any part of town on a given day are considerably below $0.010 \mathrm{WL}$, no more outdoor working levels will be measured for the rest of that day.

2. As soon as the necessary equipment is obtained, grab radon measurements will also be made outside and inside of structures at the same time as the indoor radon daughter concentrations are being measured. The data gathered will be used to determine whether radon measurements instead of working level measurements could be used for screening purposes in future surveys. 
3. Terradex type F Track Etch devices will be placed in 50 structures in which RPISU measurements are being made to determine how well the working levels determined using the Track Etch correspond to those measured with the RPISU. One Track Etch will be placed for a period of one year in each of these structures, and another will be changed every other month at the same time as the RPISU samplers are installed.

4. Beginning in February of 1981 , gamma surveys in garages and nonhabitable basements will be conducted using grid networks and measurement procedures identical to those used inside other structures (i.e., at the grid points of a $25 \mathrm{ft}^{2}$ grid). Previousiy, we had measured the gamma exposure rates during a serpentine walkthrough of the garages and non-habitable basements.

5. The Ludlum scintillometers have been fitted with earphones. The audible signal will be used in addition to the meter reading to locate residual radioactivity. 


\section{LIST OF ATTENDEES}

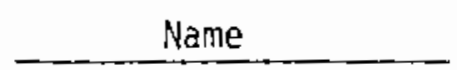

J. Micholos Abremiah

Marilyn Alkire

David Ball

Dave Bernhardt

Randy Brich

Michael L. Brown

Ray Cooperste in

Dale H. Denham

Tom Donovan

Gregory G. Eadie

John J. Endres

Bud Franz

John Giedt

Wayne Gisler

Don Groelsema

Don F. Harmon

Fred Haywood

Al Hazle

Pete Jackson

Walt Kisieleski

Gien Lane

Hal Langner

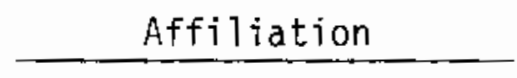

Bendix

Attorney

DOE

EPA

S.D. Dept. of Health

Colorado Dept. of Health

DOE

PNL

TVA

NRC

HUD

Colorado Dept. of Health

EPA

Bendix

Grand Junction

DOE

NRC

ORNL

Colorado Dept. of Health

PNL

ANL

Council of Energy

Resource Tribes

5660 S. Syracuse Circle

Englewood, Co 80111
Phone

(303) 242-8621 FTS. $322-9220$

(303) $861-7000$

FTS. 846-5239

FTS. $595-2469$

(605) $773-3329$

(303) 320-8333 ext. 6246

FTS 233-3639

FTS $444-0303$

(615) $755-6651$

(301) 427-4541

(303) $837-3721$

(303) 245-2400

FTS. 327-4535

(303) $242-8621$ FTS. $322-9220$

(301) 353-5221 FTS. 233-5221

(301) 443-5910

(615) 547-5830 FTS. 624-5830

(303) 320-8333 ext. 6246

(509) $376-3780$ FTS. $444-3780$

(312) $972-313 i$ FTS. 972-3737

(303) $779-4760$

(303) $245-2400$ 
Name

Craig McIntyre

Michael Momeni

Edmond $F$. Noe?, Jr.

Bob Overmyer

Richard W. Perkins

Bob Powers

Harold L. Rarrick

Ross A. Scarano

Lysle C. Schwendiman

Walt Smith

John G. Themelis

Bill Thomas

Jack Thra1]

John Tipton

Ralph wallace

Ken L. K. Weaver

John Witherspoon

Ned Wogman

Bob Wynveen

Jim Young
Affiliation

SPB

ANL

Attorney

$\mathrm{FB}$ and $\mathrm{DU}$

PNL

TVA

Sandia

NRC

PNL

ANL

DOE

Grand Junction

PNL

EPA

$E G$ and $G$

TVA

Colorado Dept. of Health

ORNL

PNL

ANL

PNL
Phone

(605) $773-366]$

(312) $972-3134$

(303) $86 !-7000$

(401) $583-3773$

(509) 376-3461 FTS. 444-3461

(307) $265-5550$ ext. 5463

(505) 844-2652 FTS. $844-2652$

(301) $427-4103$

FTS. 444-4227

(312) $972-3322$ FTS. $972-3322$

(303) 242-8621 FTS. 322-9220

(509) $376-3546$ FTS. $444-3546$

(702) 798-2462

(702) 739-0511 FTS. 598-0511

(205) 386-2991

(303) 320-8333 ext. 4325

FTS. 626-2105

(509) 376-3003 FTS. 444-3003

(312) 876-3322 FTS. 972-3322

(509) $376-4448$ FTS. $444-4448$ 
.

. 
NUREG/CR-2083

PNL-3784

\section{DISTRIBUTION}

No. of

Copies

OFFSITE

A. A. Churm

DDE Patent Division

9800 South Cass Avenue

Argonne, IL $6 \mathrm{D} 439$

225 U. S. Nuclear Regulatory Commission

Division of Technical

Information and Document Control

7920 Norfolk Avenue

Bethesda, MD 20014

2 DOE Technical Information Center

2 G. G. Eadie, Program Manager

Uranium Recovery Licensing Branch

U. S. Nuclear Regulatory Commission

Washington, D. C. 20555

N. I. Abramiuk

Bendix Field Engineering Corp.

P. 0. Box 1569

Grand Junction, CO 81502

David Ball

U. S. Department of Energy

UMTRA

Albuquerque Operations office

Albuquerque, NM 87115

D. Bernhardt

Office of Radiation Programs

Environmental Protection Agency ORP/LVF

P. 0. Box 18416

Las Vegas, NV 89114

R. Brich

Department of Health

State of South Dakota

Division of Environmental Health

Foss Building

Pierre, SD 57501
No. of

Copies

M. L. Brown

Department of Health

State of Colorado, 125 North 8th

Grand Junction, CO 81501

R. Cooperstein

Environmental and Safety

Engineering Division

U. S. Department of Energy

Washington, D. C. 20545

T. K. Donavan

Project Manager

Edgemont Mil1 Decontamination

TVA

303 Crystal Building

Chat tanooga, TN 37201

J. J. Endres

Special Assistant to the

Regional Administrator

Department of Housing and Urban

Deve iopment

Executive Tower, 1405 Curtis St.

Denver, C0 80202

G. A. Franz

Senior Health Physicist

Department of Health

State of Colorado

125 North 8th

Grand Junction, CO 81501

J. R. Giedt

Regional Radiation Representative Environmental Protection Agency

1860 Lincoln Street

Denver, CO 80295

W. D. Gisler

Bendix Field Engineering Corp.

P. 0. Box 1569

Grand Junction, CO 81501

D. H. Groelsema

U. S. Department of Energy

Washington, D. C. 20545 
No. of

Copies

D. F. Harmon

U. S. Nuclear Regulatory Commission

Washington, D. C. 20555

Fred Haywood

Health and Safety Research Division

Oak Ridge National Laboratory

P. 0. Box $X$

Oak Ridge, TN 37830

A. J. Hazle, Director

Radiation and Hazardous Waste Control Division

Colorado State Department of Health

1405 Curtis Street

Denver, C0 80202

W. Kisieleski

Argonne National Laboratory 9700 South Cass Avenue

Argonne, IL 60439

G. Lane

Council of Energy

Resource Tribes

5660 South Syracuse Circle

Englewood, CO 80111

H. Langner

Department of Health

State of Colorado

125 North 8th

Grand Junction, CO 81501

C. McIntyre

State Planning 8ureau

Capitol Building

Pierre, SD 57501

M. Momeni

Argonne National Laboratory 9700 South Cass Avenue

Argonne, IL 60439
No. of

Copies

R. Overmeyer

Ford, Bacon \& Davis

P. 0. Box 8009

Salt Lake City, UT 84108

R. P. Powers

TVA

P. 0. Box 2957

Casper, WY 82602

H. Rarrick

Sandia Area Office

U. S. Department of Energy

P. 0. Box 5400

Albuquerque, NM 87115

R. A. Scarano

U. S. Nuclear Regulatory Commission

Washington, D. C. 20555

W. Smith

Argonne National Laboratory

9700 South Cass Avenue

Argonne, IL 60439

J. G. Themelis

Grand Junction Office

U. S. Department of Energy

P. 0. Box 2567

Grand Junction, CO 81502

J. Thrall

Office of Radiation Programs

Environmental Protection Agency

ORP/LVF

P. 0 . Box 18416

Las Vegas, NV 89114

J. Tipton

EG\&G, Incorporated

P. 0. Box 1912

Mai1 Stop P-01

Las Vegas, NV 89101 
No. of

Copies

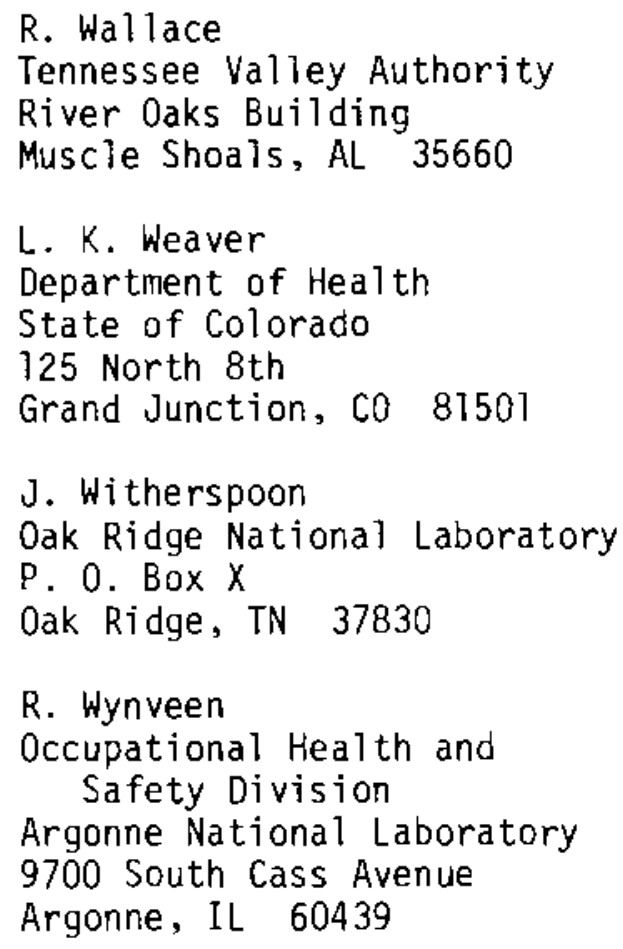

ONSITE

27 Pacific Northwest Laboratory

P. 0. Jackson (10)

J. M. Nielsen

R. W. Perkins (5)

L. C. Schwendiman

V. W. Thomas

N. A. Wogman

J. A. Young

Technical Information (5)

Publishing Coordination (2) 



\begin{tabular}{|c|c|}
\hline $\begin{array}{l}\text { U.S. NUCLEAR REGULATORY COMMISSION } \\
\text { BIBLIOGRAPHIC DATA SHEET }\end{array}$ & $\begin{array}{l}\text { 1. AEPORT NUMBER (A ssigned by ODC) } \\
\text { NUREG/CP-0021 } \\
\text { PNL-3784 }\end{array}$ \\
\hline \multirow{2}{*}{$\begin{array}{l}\text { 4. TITLE AND SUQTITLE (Ada Volume No., if apprapriarel } \\
\text { Conference Proceedings for } \\
\text { Workshop on Radiological Surveys in Support of the } \\
\text { Edgemont Clean-up Action Program }\end{array}$} & 2. (Leave blank) \\
\hline & 3. RECIF \\
\hline $\begin{array}{l}\text { 7. AUTHORiSi } \\
\text { J. A. Young, P. 0. Jackson, V. W. Thomas, } \\
\text { L. C. Schwendiman, R. W. Perkins }\end{array}$ & \begin{tabular}{|c|c|} 
5. DATE REPORT COMPLE TED \\
MONTH \\
Apri 1
\end{tabular} \\
\hline \multirow{4}{*}{$\begin{array}{l}\text { 9. PERFORMING ORGANIZMTION NAME AND MAILING ADDRESS (Include } Z_{i p} \text { Code) } \\
\text { Pacific Northwest Laboratory } \\
\text { Richland, WA } 99352\end{array}$} & DATE REPOAT ISSUED \\
\hline & $\begin{array}{l}\text { MONTM } \\
\text { October }\end{array}$ \\
\hline & 6. (Leave biank) \\
\hline & 8. $R E$ \\
\hline \multirow{2}{*}{$\begin{array}{l}\text { 12. SPONSORING ORGANiZATION NAME AND MAILING ADDRESS (Include Z } 20 \text { Code) } \\
\text { Office of Nuclear Material Safety and Safeguards } \\
\text { U.S. Nuclear Regulatory Commission } \\
\text { Washington, DC } 20555\end{array}$} & 10. PROJECT/TASK/WOAK UNIT NO. \\
\hline & \\
\hline \multicolumn{2}{|l|}{$\begin{array}{l}\text { 13. TYPE OF REPORT } \\
\text { Conference Report }\end{array}$} \\
\hline $\begin{array}{l}\text { 15. SUPPLEMENTARY NOTES } \\
\text { None }\end{array}$ & 14. (Leave biank) \\
\hline \multicolumn{2}{|c|}{ 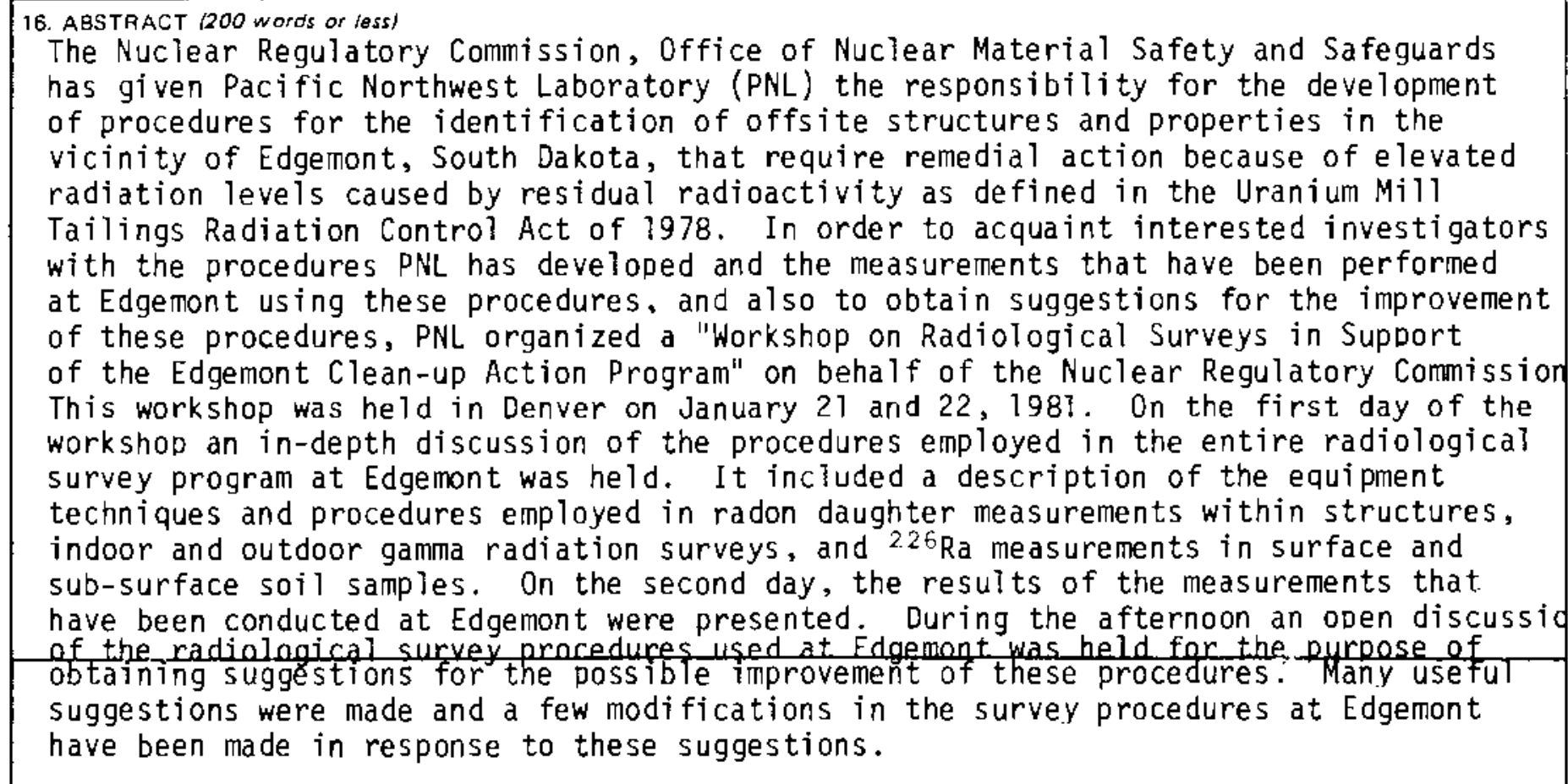 } \\
\hline
\end{tabular}

17b. IOENTIFIERS/OPEN-ENOED TERMS

18. AVAILABILITY STATEMENT

Unlimited

\begin{tabular}{|c|c|}
\hline 19. SECURITY CLASS (This report) & 21. NO. OF PAGES \\
\hline 2QuSE & $\begin{array}{l}\text { 22. PRICE } \\
\text { \$ }\end{array}$ \\
\hline
\end{tabular}




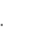

